\title{
Los gobiernos lencinistas en Mendoza. Salud pública y vivienda popular, 1918-1924
}

\author{
Rodolfo Richard-Jorba ${ }^{1}$ \\ INCIHUSA-CONICET \\ Universidad Nacional de Cuyo
}

\begin{abstract}
Resumen
En febrero de 1918 se abrió en Mendoza un nuevo ciclo político: comenzaron los gobiernos de la Unión Cívica Radical (UCR) acaudillados por uno de sus fundadores, José Néstor Lencinas, y por su hijo Carlos Washington, con intervenciones federales intermedias y otras que clausuraron el período del segundo antes de que concluyera su mandato. El discurso antioligárquico, el trato directo con los trabajadores y sectores populares en general, junto con la sanción de diversas leyes de las que éstos resultaban beneficiarios determinaron un mayoritario apoyo que se mantuvo durante toda la década de 1920, reflejado en grandes triunfos electorales.

Nos preguntamos si los Lencinas provocaron una ruptura clara y profunda con el pasado de los gobiernos conservadores o gobiernos oligárquicos que durante más de medio siglo ejercieron el poder y modernizaron Mendoza o, si, por el contrario, tuvieron continuidades. Esta es una premisa para guiar nuestra investigación, que avanza lentamente porque la muy escasa bibliografía existente sobre el lencinismo, obliga a trabajar en una reconstrucción histórica a base de fuentes diversas. El artículo está centrado en establecer si las condiciones de vida de las bases sociales de los Lencinas mejoraron en materia de salud y vivienda como producto de políticas innovadoras o si éstas significaron una continuidad de las fijadas por el régimen conservador.
\end{abstract}

Palabras clave:: Lencinismo - sectores populares - salud - vivienda

\begin{abstract}
A new political cycle was opened in Mendoza on February 1918: the government of the Union Cívica Radical directed by one of its leaders José Nestor Lencinas and his son Carlos Washington, with intermediate federals and others that close the period of the later before the end of his mandate. The anti oligarchic discourse and the direct treatment with the working class and the common people along with the approval of several laws that benefited them, determined a great support during the 1920 decade which was reflected in great electoral triumphs.

We asked ourselves if the Lencinas provoked a clear and a profound break with conservative or oligarchic governs that exerted for more that half a century the power and modernization of the province of Mendoza, or, if the had had continuity. This is a premise which guides our research, which due to
\end{abstract}

1 INCIHUSA-CONICET y U.N. de Cuyo. E-mail: rrichard@mendoza-conicet.gov.ar

RICHARD JORBA, Rodolfo, "Los gobiernos lencinistas en Mendoza. Salud pública y vivienda popular, 1918-1924" en Avances del Cesor, Año VIII, Nº 8, 2011, pp. 31-62. 
the scarce Lencinismo's bibliography forces us to work in a historical reconstruction based on diverse sources.

The article aims at determining if the well being of the population improved regarding health care and housing because of the new policies or because they were just a continuity of the ones fixed by the former conservatory regime.

Key words: Lencinismo - working class - health - housing

En febrero de 1918 se abrió en Mendoza un nuevo ciclo político: comenzaron los gobiernos de la Unión Cívica Radical (UCR) acaudillados por uno de sus fundadores, José Néstor Lencinas, y por su hijo Carlos Washington, con intervenciones federales intermedias y otras que clausuraron el período del segundo antes de que concluyera su mandato. El discurso antioligárquico, el trato directo con los trabajadores y sectores populares en general, junto con la sanción de diversas leyes de las que éstos resultaban beneficiarios determinaron un mayoritario apoyo que se mantuvo durante toda la década de 1920, reflejado en grandes triunfos electorales. ${ }^{2}$ Disidencias y enfrentamientos con Yrigoyen conducirían a la separación de la UCR y a la fundación de la UCR Lencinista, vinculada con el radicalismo antipersonalista.

Nos preguntamos si los Lencinas provocaron una ruptura clara y profunda con el pasado de los gobiernos conservadores o gobiernos oligárquicos que durante más de medio siglo ejercieron el poder y modernizaron Mendoza. Esta es una premisa para guiar nuestra investigación, que avanza lentamente porque la muy escasa bibliografía existente sobre el lencinismo, obliga a trabajar en una reconstrucción histórica a base de fuentes diversas. ${ }^{3}$ José Néstor Lencinas, como buen radical de la época, se consideraba un revolucionario ${ }^{4}$ que

2 Sobre este período, véase la única obra que lo ha abordado específicamente en sus facetas políticas, económicas y sociales: RODRÍGUEZ, Celso, Lencinas y Cantoni. El populismo cuyano en tiempos de Yrigoyen, Editorial de Belgrano, Buenos Aires, 1979. Véase también a LACOSTE, Pablo, La Unión Cívica Radical en Mendoza y en la Argentina (1890-1946), Ediciones Culturales de Mendoza, Mendoza, 1994. El capítulo II da un panorama del lencinismo, en particular desde el plano político e institucional. Asimismo, véase el ensayo de OLGUÍN, Dardo, Dos políticos y dos políticas. Emilio Civit-José Néstor Lencinas. La oligarquía liberal y la democracia popular, Mendoza, 1956. Se traza allí una semblanza de estos dos dirigentes paradigmáticos y las diferencias en sus modos de hacer política, concepciones, etc.

3 Entre las principales, los Mensajes de los gobernadores a la Legislatura y los Registros Oficiales. También, los clásicos álbumes dedicados a resaltar las virtudes de los gobernantes. Es clave, además, apelar a la prensa. Hubo en la década de 1920 una gran abundancia de diarios y periódicos. Para esta investigación, hemos revisado un órgano claramente opositor, editado por el socialismo, El Socialista, y Los Andes, diario tradicional, crítico con José Néstor, más moderado con el hijo, aproximándose a lo que hoy consideramos prensa independiente.

4 Un artículo sobre el proceso generado contemporáneamente por el radicalismo en Jujuy, aclara que 
venía a regenerar la política apoyado por el pueblo (básicamente los sectores populares) y a demoler el pasado oligárquico transformando el Estado (y sus instituciones) para ponerlo al servicio de los trabajadores y de los productores. ${ }^{5}$

José Néstor Lencinas (el Gaucho) falleció en enero de 1920, a dos años de haber sido elegido y después de haber soportado en ese corto tiempo intervenciones federales motivadas, precisamente, por esas posiciones revolucionarias, que lo llevaron a avasallar las instituciones de la Constitución y perseguir con extrema violencia a sus opositores. En 1922 su hijo Carlos Washington (el Gauchito) fue elegido gobernador, cargo que ocupó hasta ser intervenido federalmente (octubre de 1924). El último turno lencinista estuvo a cargo del gobernador Alejandro Orfila, quien asumió en febrero de 1926 y cuyo período gubernativo no será analizado en este trabajo.

El lencinismo fue un temprano fenómeno populista en el contexto nacional. Si bien no hay acuerdo entre científicos sociales para definir al populismo, tal como sucede con la región entre los geógrafos, sí hay elementos comunes que le son atribuidos desde diferentes posiciones académicas: la existencia de un líder en comunicación directa con las masas; las políticas reformistas que adopta; el escaso o nulo apego a las instituciones; una visión nacionalista de la economía y la política; la división de la sociedad entre nosotros y ellos, aplicación de la lógica dicotómica amigo-enemigo; carácter no clasista del movimiento, etc. ${ }^{6}$ En efecto, los Lencinas plantearon siempre estar al servicio de los trabajadores, obreros, peonadas, de los pobres en general, sectores que seguían fielmente a sus caudillos. El Gaucho, según su biógrafo y exégeta, imaginaba un nuevo mundo que surgiría rápidamente

el concepto de revolución de los radicales no cuestionaba el sistema establecido de dominación social; sólo implicaba un cambio democrático reformista y distributivo. Véase FLEITAS, María Silvia, "El radicalismo en Jujuy de los años 20. Miguel A. Tanco, el 'hombre que levantará al obrero y hará feliz la vida del pueblo"', disponible en historiapolitica.com/datos/biblioteca/fleitas.pdf (fecha de consulta: 8-9-2011), pp. 1-27.

5 NIETO RIESCO, Julio, José Néstor Lencinas (Jefe de Estado), Mendoza, 1926. Nieto Riesco fue Fiscal de Estado y ministro de Hacienda de la provincia; pese a su condición de partidario y contemporáneo, muestra cierta objetividad en el tratamiento del personaje que merece ser destacada. Esta discursividad parece repetirse en otras provincias, como San Juan, con los Cantoni, o Jujuy, con Miguel Tanco (Véase RODRÍGUEZ, Celso, Lencinas y Cantoni..., Op. Cit.; y FLEITAS, María Silvia, "El radicalismo en...", Op. Cit.).

6 De la muy numerosa bibliografía acerca del populismo resultan esclarecedoras las obras de MOSCOSO PEREA, Carlos, El populismo en América Latina, Centro de Estudios Constitucionales, Madrid, 1990; y MACKINNON, María M. y PETRONE, Mario A., (compiladores), Populismo y Neopopulismo en América Latina. El problema de la Cenicienta, EUDEBA, Buenos Aires, 1999, en especial la Introducción, escrita por los compiladores, pp. 11-55, y el clásico artículo de Juan Carlos Torre, "Interpretando (una vez más) los orígenes del peronismo", pp. 173-195. 
en la primera posguerra. En ese mundo las cuestiones económicas serían el eje de conflictos entre ideas y sentimientos.

La lucha la presagiaba fuerte entre las dos fuerzas que la sustentan: conservadora, reaccionaria, capitalista, la una, bregando por el mantenimiento del orden social y económico existentes; y liberal, radical obrera, la otra, buscando una organización social más justa, más igualitaria, más concorde con los sacrificios de la lucha...

El núcleo dirigencial que respondía a los Lencinas, muchos de ellos universitarios como sus jefes, movilizaba a las masas a través del empleo público, el reconocimiento de sus valores, la organización de banquetes y la aplicación de políticas para beneficiarlas. ${ }^{8} \mathrm{La}$ ideología era difusa. La regeneración de la política, el enfrentamiento del pueblo contra la oligarquía, las invocaciones a la patria, etc., estaban en el discurso, que mezclaba pensamientos disímiles como los de Tolstoi, Lenin o Le Bon con recepciones ofrecidas oficialmente a Leopoldo Lugones. En los hechos, la represión de la oposición (socialistas) y de ciertos periodistas, el enfrentamiento con organizaciones obreras, la cooptación de dirigentes o la persecución e internación de los mendigos y otros marginados para limpiar la ciudad capital, contrastaban con leyes sociales de avanzada y con el apoyo a los productores vitivinícolas, en especial los más débiles, los viñateros sin bodega.

\section{Los sectores populares en el orden conservador}

El desarrollo capitalista mendocino se estructuró sobre la agroindustria vitivinícola desde la década de 1880 , con una producción en gran escala para abastecer un mercado nacional en permanente expansión. Entre 1914 y 1918 estaban en producción unas 70.000 ha. con vid en un marco de subdivisión de la tierra, lo que promovía la ampliación de los estratos medios de la sociedad. ${ }^{9}$ Las bodegas se multiplicaron: de 341 en 1888, todas muy

7 NIETO RIESCO, Julio, José Néstor ... (Jefe de Estado)..., Op. Cit., p. 133.

8 Los Lencinas eran abogados, profesión que compartían con diversos colaboradores, entre otros, Julio Nieto Riesco, Fiscal de Estado, Ministro de Hacienda biógrafo y exégeta del Gaucho; hombre de ideas claramente progresistas. Hubo, además, médicos que elaboraron planes de salud (niñez, enfermedades infecto-contagiosas, etc.), como el Dr. Bernardo A. Ferreyra. Pero el centro del núcleo dirigencial tal vez corresponda atribuirlo al Ing. Leopoldo Suárez, quien ocupara durante estos gobiernos el estratégico Ministerio de Industria y Obras Públicas. Además de un notable técnico, fue un intelectual con gran capacidad ejecutiva y concentró en sus manos el diseño y aplicación de las políticas económicas intervencionistas que revitalizaron la alicaída economía vitivinícola. En su gestión, Suárez priorizó las infraestructuras económica y social, lo que sin dudas amplió el apoyo popular al lencinismo.

9 Entre 1881 y 1900 se iniciaron 2.900 explotaciones vitícolas, $67 \%$ de las cuales tenía menos de 5 ha; hacia 1914, los viñedos registrados eran 6.160 y el 80\% tenía menos de 25 ha (RICHARD-JORBA, 
pequeñas (menos de $1.000 \mathrm{Hl}$. de capacidad), se llegó en 1914, a casi 1.400, varias de las cuales elaboraban entre 150.000 y $250.000 \mathrm{Hl}$. La producción total de vinos acompañaba la enorme expansión de la demanda interna: $927.000 \mathrm{Hl}$. en 1899 y $4.310 .000 \mathrm{Hl}$. en $1914 .{ }^{10}$ Los impuestos al sector financiaban más de la mitad del presupuesto de la provincia.

La vitivinicultura generó demandas de otros bienes, en parte satisfechas con la instalación de talleres de servicios que comenzaron a fabricar repuestos y equipos de baja complejidad para bodegas, dando origen a un incipiente brote industrial. ${ }^{11}$

En este contexto, el mercado de trabajo se volvió más grande y complejo, como fuera registrado en el Censo de 1895. Nuevas categorías socioprofesionales de trabajadores y empleados calificados para atender operaciones industriales (electricistas, maquinistas, enólogos...) o diversos servicios, se reforzaron en 1914. Sin embargo, los trabajadores con empleo precario, muchas veces temporario, agrupados como peones o jornaleros, y el personal del servicio doméstico, constituían amplias mayorías en el mundo del trabajo y estaban en la base de la pirámide social. ${ }^{12}$

Entre los años 1890 y finales de la segunda década del siglo XX, la prensa registraba de forma unánime el grave problema que representaba el incesante aumento de los precios de los principales bienes de consumo para la subsistencia de los sectores populares. Efectivamente, los trabajadores y sus familias se enfrentaban cotidianamente al drama del creciente costo de vida, cuestión que obligaba a intensificar el trabajo de todo el núcleo familiar, incluyendo los niños. ${ }^{13}$

El precio de los alquileres por insuficiencia de la oferta era otra constante que afectaba de manera creciente el ingreso de los trabajadores y la prensa denunciaba que el costo de vida en ascenso provocaba desaliento e incidía en la emigración de población. En efecto, mientras los precios subían, los jornales de los mayoritarios trabajadores no calificados (peones rurales y urbanos, mensuales o temporarios; también las mujeres y los menores) se mantuvieron estables en términos nominales durante casi tres décadas, entre $1890 \mathrm{y}$ 1918, no superando los $\$ 2$ por día como máximo. En ese extenso período la conflictividad social tuvo amplias manifestaciones, con un movimiento obrero crecientemente organizado,

Rodolfo et. al., La región vitivinícola argentina. Transformaciones en el territorio, la economía y la sociedad, 1870-1914, UNQuilmes, Buenos Aires, 2006), Cap. II.

10 Ibídem.

11 PÉREZ ROMAGNOLI, Eduardo, “Contribuciones para una geografía histórica de Mendoza: las industrias inducidas por la fabricación de vino entre 1880 y 1930”, en Revista de Estudios Regionales, CEIDER, Mendoza, 1996, Nº 15-16, pp. 53-88.

12 El empleo precario alcanzaba al 57\% del total de la población en actividad (RICHARD-JORBA, Rodolfo et al, La región vitivinícola..., Op. Cit., p. 112).

13 RICHARD-JORBA, Rodolfo, Empresarios ricos, trabajadores pobres. Vitivinicultura y desarrollo capitalista en Mendoza (1850-1918), Prohistoria Ediciones, Rosario, 2010. 
en busca de mejores condiciones de trabajo y mayores ingresos, además de huelgas por solidaridad. Las condiciones de vida de los sectores populares eran muy precarias, con hacinamiento, promiscuidad, déficit alimentarios y muy altas tasas de morbi-mortalidad, especialmente la infantil. ${ }^{14}$

\section{Las gestiones lencinistas y los sectores populares}

En 1918, la Ley 732 sancionada por el novel gobierno de José Néstor Lencinas provocó un significativo impacto en las relaciones laborales hasta entonces imperantes. Esa ley fijaba un jornal mínimo de $\$ 2,50$ para los trabajadores estatales y los que cumplieran trabajos para el sector público, con una jornada máxima de 8 horas. También esa jornada se aplicaría a los privados, para quienes se fijaba un jornal mínimo de $\$ 2$ (es decir, el máximo que percibían hasta ese momento), a fin de evitar que los patrones disminuyeran esos ingresos acompañando la reducción del tiempo de labor. ${ }^{15}$ Esto último no entró en vigencia en el período estudiado porque el Poder Ejecutivo no reglamentó la ley sino hasta $1926 .{ }^{16} \mathrm{De}$ modo que la nueva norma tuvo inicialmente una incidencia relativa en tanto se aplicó sólo al sector estatal, pero marcó un hito muy destacado al establecer la jornada máxima y la intervención del Estado como regulador de las relaciones entre capital y trabajo. Habilitó asimismo una serie de conflictos de obreros privados que reclamaban jornadas laborales y salarios en función de aquella legislación. En años posteriores el Estado comenzaría a controlar de manera efectiva (aunque parcial y muy gradual) cuando se tornara operativa otra creación del Gaucho (Ley 731 de 1918), la Inspección General de Trabajo (luego Departamento Provincial de Trabajo), durante la gobernación de Carlos Washington Lencinas.

El costo de la vida, sin embargo, continuó agobiando a los sectores populares, con brevísimos momentos de cierto equilibrio entre gastos e ingresos. Aun cuando se requiere una minuciosa revisión de fuentes para obtener datos sobre precios que posibiliten construir series o, al menos, listas en algunos años seleccionados, un informe oficial del último gobierno lencinista permite una aproximación. Ese documento presentó un esquema de la relación costo de vida/salarios entre 1916 y 1927. Se tuvo en cuenta el ingreso de un

\section{Ibídem.}

15 El gobernador Alejandro Orfila intentó en 1927 fijar el salario mínimo en $\$ 4,50$ por día porque todavía se mantenían jornales de 1918 -y de fines del siglo XIX- pese al aumento del costo de vida (Ley 922, declarada inconstitucional por la Corte Suprema de Justicia de la Nación en 1929).

16 Alejandro Orfila reglamentó la Ley 732 por decreto del 20-2-1926, días después de asumir el cargo. Extendió la jornada máxima a todo el ámbito laboral, urbano y rural, y prohibió a los patrones descontar de los salarios suministros que podrían haber sido entregados a los trabajadores, lo que sugiere la pervivencia de salarios de tipo arcaico, cubiertos en parte en especie. El permanente ascenso de los precios denunciado por la prensa y documentos oficiales seguramente habría reforzado esta pervivencia perjudicando a los trabajadores. 
obrero con una familia de cinco miembros (tres menores). Para el período que nos ocupa, esa relación habría sido neutra sólo en 1919 y 1922, mostrando desbalances contrarios a la situación de los sectores populares en 1918, 1920, 1921, 1924 y $1925 .{ }^{17}$ Sin embargo, una investigación reciente señala cierta incompatibilidad con estas cifras. ${ }^{18}$ Además, la revisión de los Presupuestos de la provincia entre 1915 y 1924 muestra otra realidad, confirmando aquella incompatibilidad: hay numerosos cargos del Estado con salarios muy bajos y sólo algunos trabajadores más calificados habrían podido sustentar sus consumos. ${ }^{19} \mathrm{Y}$ si en el Estado persistían esos magros ingresos, resulta difícil suponer que en el sector privado serían mejores, al menos entre los mayoritarios trabajadores no calificados o escasamente preparados.

¿Qué motivaba entonces a una considerable mayoría de la población, perteneciente sobre todo a los predominantes sectores populares, a seguir a los Lencinas? ${ }^{20}$ Esta pregunta carece de una respuesta unívoca; por el contrario, deberán buscarse respuestas parciales pero convergentes para explicar un fenómeno que parece bastante complejo, que excede

17 ZULOAGA, Manuel A., Salario mínimo, Talleres Gráficos J. Peuser, Mendoza, 1927, pp. 9 y 112. Zuloaga era Ministro de Gobierno y Presidente de la Comisión de Salarios instituida por el gobernador Orfila para estudiar la situación de los trabajadores y fijar un salario mínimo en la provincia. Este estudio indica mediante un gráfico que en 1918, con un jornal de $\$ 2$, la familia obrera necesitaba gastar \$ 3; en 1919 esa relación se habría equilibrado al mejorar el jornal a \$ 3; en 1921 se abrió una brecha: \$ 3 y \$3,50, restableciéndose el equilibrio por un descenso de precios en 1922-1923 (\$3 para cada parte), no explicado ni demostrado con evidencia en el documento. Finalmente, desde 1924, la brecha se hizo cada vez más ostensible, con un jornal fijo de $\$ 3$ y gastos que crecieron de $\$ 4$ en 1924 a $\$ 5$ en 1925.

18 Si para 1910-1911 hemos calculado un presupuesto de gastos de un matrimonio con dos hijos sin escolaridad en $\$ 103,11$ mensuales, una década más tarde resultaría imposible que una familia de 5 miembros subsistiera con $\$ 3$ por día (Véase RICHARD-JORBA, Rodolfo, Empresarios ricos..., Op. Cit. p. 256).

19 Por ejemplo, un cochero o un ordenanza, fueron cargos que pasaron de cobrar $\$ 60$ entre 1915 y 1918 ( \$ 2 por día), a \$ 100 (poco más de \$ 3 por día) entre 1922 y 1924, lo que muestra incrementos producidos por el lencinismo. Pero otros trabajadores, como el vigilante de policía, no modificó su salario desde 1915 a 1924 (\$ 90); el agente policial de campaña, que ganaba \$ 70 en el período conservador y comienzos del lencinismo, recibió sólo \$ 5 de aumento en 1923 (menos de un 10\%); enfermeras de hospitales pasaron en esos años de $\$ 60$ a $\$ 75$ en 1923; y los peones y costureras de hospitales mantuvieron sin modificaciones sus ingresos ( $\$ 50$ entre 1915 y 1924). (Véanse las leyes de Presupuesto de Gastos de la Provincia de Mendoza, 1915-1922 [1916-1922 presupuesto prorrogado]; 1923 y 1924).

20 En sucesivos actos electorales tanto José Néstor como su hijo superaron por márgenes amplísimos a la oposición conservadora, socialista y de la propia disidencia radical (RODRÍGUEZ, Celso, Lencinas y Cantoni..., Op. Cit.; LACOSTE, Pablo, La Unión Cívica Radical..., Op. Cit., p. 49, reproduce en un cuadro las cifras aportadas por Rodríguez). 
el objeto puntual de esta investigación. Y esto es así, porque la empatía de los Lencinas con los sectores populares y el carisma con que los cautivaban superan la mera respuesta material de un gobierno a necesidades de sus bases sociales. Una ideología enteramente difusa, como la radical, no era posiblemente factor de atracción masiva. Tampoco la proclamada regeneración de la política y sus prácticas. Es, más bien, el trato interpersonal ${ }^{21}$ y la articulación líder-seguidores o líder-masa, en una relación inorgánica, a diferencia -sin perjuicio de ciertas similitudes- de lo que sucedería años más tarde con el peronismo y su negociación con el movimiento obrero organizado para consolidarse como fuerza política. ${ }^{22}$ Y en esa relación, los sectores populares se sintieron interpretados, apoyados, considerados, tratados como seres humanos y como sujetos de derecho o ciudadanos por el nuevo poder político, a diferencia de lo padecido durante más de medio siglo de régimen oligárquico, de orden conservador.

Un repaso a las ideas de José Néstor respecto de los sectores populares es un buen punto de partida para aproximarnos a su actuación con el objetivo de establecer si hubo coherencia entre pensamiento y acción, justificativo, en parte, del respeto reverencial que le profesaron sus partidarios.

En la campaña electoral de 1917, con vistas a las elecciones que en enero del año siguiente lo consagrarían gobernador, el Gaucho dio a conocer un Manifiesto al pueblo de la Provincia de Mendoza en el que expresaba algunas de sus principales ideas y formulaba propuestas para la futura acción de gobierno si resultaba electo. Nos interesa destacar, por su estrecha complementación, las referidas a la economía -en tanto generadora de riqueza y empleo o de la pérdida de ambos-, y las que atienden al mundo de los trabajadores. ${ }^{23}$

Lencinas destacaba que había una crisis profunda:

... intensa, que la soporta en primer término, la viña, que es nuestra principal y hoy casi única fuente de producción. Se hace, pues, indispensable no sólo normalizar esta situación, sino también buscar... nuevas fuentes de producción que vengan a crear un

21 Una biografía política del Gaucho destaca que desde su estudio de abogado y siendo muy joven defendió en los tribunales a los sectores populares perseguidos por la justicia o los gobiernos oligárquicos, lo que le granjeó el reconocimiento y la admiración de los marginados, que fueron convirtiéndose en sus seguidores fieles cuando se incorporó a la U.C.R. en los años 1890 y cuando se convirtió en el jefe indiscutido de la misma (NIETO RIESCO, Julio, José Néstor Lencinas (Jefe de Partido), Mendoza, 1926). Su hijo heredó parte de esa tradición y, a su manera, la siguió, aunque tuvo menos consideraciones morales que su padre (NIETO RIESCO, Julio, José Néstor.... (Jefe de Estado)..., Op. Cit.).

22 MACOR, Darío y TCACH, César (editores), La invención del peronismo en el interior del país, UNLitoral, Santa Fe, 2003. En especial, véase la Introducción, elaborada por los editores.

23 FALCÓN, Ricardo, La Barcelona Argentina. Migrantes, Obreros y Militantes en Rosario, 18701912, Laborde Editor, Rosario, 2005. 
estímulo para el capital y la concurrencia del brazo trabajador que, en buen número, ha salido de la provincia como causa evidente de esa misma crisis. $^{24}$

Planteaba para salir de la crisis, entre otras cuestiones, repoblar los campos del llano y la montaña con ganadería vacuna para el abastecimiento interno, recuperar las antiguas superficies alfalfadas para engordar ganado y exportarlo a Chile, como sucedía antes de la modernización vitivinícola de fines del S. XIX. Esto implicaba una vuelta a un pasado que estaba irremisiblemente superado por la especialización complementaria del espacio central argentino que habían desarrollado las economías regionales extrapampeanas; mostraba, sin dudas, una escasa visión del funcionamiento de la economía nacional y su sistema de transporte ferroviario, que tornaba innecesario el engorde local de los animales en caso de que Chile volviera a demandar ganado como antaño. ${ }^{25}$ Como elemento moderno proponía algo que se cumpliría años más tarde: sacrificar el ganado en Mendoza para agregar valor a esas posibles exportaciones, para lo cual “... es indispensable la construcción de mataderos con todos los adelantos modernos que llenen esa necesidad y de donde pueden derivarse otras grandes y pequeñas industrias."26 También pensaba en instalar frigoríficos para conservar frutas, legumbres y otros artículos porque opinaba, con buen criterio, que los mismos eran enviados a Buenos Aires para su conservación y reintroducidos luego en Mendoza con mayores costos. El frigorífico para la carne debería abastecer a toda la región cuyana y a Chile, compitiendo con sus similares instalados en Buenos Aires, Santa Fe y Entre Ríos, una idea más que ignoraba el contexto económico nacional. Otra propuesta era desarrollar plantaciones de remolacha azucarera para producir localmente azúcar y abastecer a la industria conservera que debería instalarse. Proponía también la instalación de fábricas de vidrio que, empleando materia prima local, produjeran envases para el vino y el agua mineral; y de papel, para aprovechar como materia prima los sarmientos de la viña empleados hasta entonces sólo como combustible. Ideas no descabelladas pero que no tenían en cuenta las escalas productivas requeridas para tornar rentables las inversiones necesarias, que no eran menores. En suma, aunque deberemos ampliar la investigación en

24 "Manifiesto al pueblo de la Provincia de Mendoza", transcripto en NIETO RIESCO, Julio, José Néstor... (Jefe de Estado)..., Op. Cit. p. 244.

25 La venta de ganado en pie a Chile decayó en el comienzo del siglo XX y si bien tuvo altibajos, la tendencia fue descendente hasta prácticamente desaparecer en la década de 1930. En el momento en que Lencinas lanzaba su Manifiesto, la exportación era ínfima: poco más de 15.000 vacunos en 1917; unos 8.500 en 1918 y apenas 300 en 1919 (Síntesis de los Anuarios de la Dirección General de Estadística de la Provincia de Mendoza correspondiente a los años 1915-1922, Peuser, Buenos Aires, 1923, p. 169).

26 “Manifiesto al pueblo...", Op. Cit., pp. 244-245. El matadero, inaugurado por Carlos Washington, sólo abastecería al mercado local. 
el futuro, su posición económica parecía orientada casi a una autarquía de la provincia, una forma de nacionalismo económico. Lo expresaba de modo contundente:

Delineada a grandes rasgos la situación actual de la provincia, debemos llegar no sólo a su regeneración institucional, sino también a una orientación... que aseguren la completa independencia económica de Mendoza al proceder a la industrialización de sus ricos productos. ${ }^{27}$

En materia agrícola, Lencinas proponía "La colonización de latifundios y tierras labradas, divididas en pequeñas parcelas con venta directa al pequeño agricultor...", para lo cual habría de crearse un banco agrícola mixto "sin tener la influencia perniciosa de la política... como sucede hoy con el actual Banco de la Provincia...", que tenía inmovilizado el 67\% de su capital "entre 16 deudores afiliados al viejo régimen," ${ }^{28}$ sin prestarle lo suficiente a agricultores y viñateros y sí a los oligarcas.

Para esos representantes del viejo régimen, el pueblo es la gauchocracia, la chusma innoble, la turba incoherente, que debe soportar... el saqueo hecho con toda impunidad... ${ }^{29}$

Proponía, entonces, liquidar ese Banco de la Provincia y crear el Banco Agrícola. Todas estas propuestas quedaron sólo como expresiones de buenos deseos. No hubo transformación agraria promovida por el Estado sino la subdivisión espontáneamente llevada a cabo por el mercado; tampoco se instalaron las fábricas de azúcar, vidrio, papel, etc. Y lo que parecería haber estado presente en su intermitente gobierno ${ }^{30}$ era el discurso antioligárquico, acompañado de acciones de persecución de adversarios y escaso respeto a la institucionalidad ya mencionados, sin que faltaran casos graves de corrupción ${ }^{31}$ y nepotismo.

Respecto de la mejora social, Lencinas prometía ocuparse de la

... salubridad pública. La mortalidad infantil en los últimos años representa una proporción que verdaderamente espanta.....Los hombres de ese funesto régimen de 50 años... jamás se ocuparon de cuidar a ese pueblo ... ${ }^{32}$

Estas últimas palabras no se correspondían con los hechos. Sin duda que la mortalidad

27 Ibídem, p. 260.

28 Ibídem, p. 249.

29 Ibídem, p. 250.

30 El gobierno de José Néstor Lencinas recibió las intervenciones federales de Tomás de Veyga (febrero/abril de 1919) y Perfecto Araya (mayo/junio de 1919). El gobernador falleció en ejercicio del cargo, el 20 de enero de 1920, un año antes de concluir su mandato.

31 RODRÍGUEZ, Celso, Lencinas y Cantoni..., Op. Cit.

32 "Manifiesto al pueblo...", Op. Cit., pp. 251-252.

40 
infantil era altísima, pero no era cierto que los hombres del funesto régimen no se hubieran ocupado. Por el contrario, hasta 1914, las tasas registradas, con oscilaciones, presentaban una clara tendencia a la baja, aun cuando fueran significativamente altas. ${ }^{33}$ Pero esa tendencia parece interrumpirse en 1916-1917, años en que se presenta un muy brusco ascenso; al contrario, se inicia en 1918, con los gobiernos lencinistas, un gradual descenso, como veremos más adelante (Cuadro 1).

Sin dejar de valorar el descenso de la tasa de mortalidad infantil $(21,8 \%$ entre 1916 y 1925), debemos destacar que las causas que provocaban la muerte de niños de hasta 5 años de edad, se mantenían prácticamente sin variantes respecto del período 1903-1914, ${ }^{34}$ como se verá más adelante. En efecto, anticipemos que las principalísimas causas de muerte de niños seguían siendo la diarrea y la enteritis (32\% del total de defunciones de niños en 1916 y $30 \%$ en 1925), ${ }^{35}$ indicio de que las condiciones de vida de los sectores populares no habían experimentado cambios significativos en orden a la higiene, la vivienda y la nutrición.

En el Manifiesto, Lencinas también anunciaba una política de viviendas para los sectores populares mediante la construcción de "casas baratas para el obrero, a fin de que con los suyos habite en condiciones higiénicas, adquiriendo con el mismo alquiler la casa que ocupe..." ${ }^{36}$ y señalaba que eso sería obra del gobierno radical que contaba ya con capitales que se le habían ofrecido. En este aspecto no hubo concreciones durante las gestiones del padre y del hijo; y las muy deficientes condiciones de habitabilidad en las ciudades (ranchos, conventillos, pensiones...) continuaron como con los gobiernos del régimen. ${ }^{37}$

Salud y vivienda, son las cuestiones que abordamos con mayor amplitud para establecer si hubo o no una real mejora en las bases sociales que sustentaron el fenómeno lencinista.

\section{La gestión de José N. Lencinas}

Una vez en posesión del cargo de gobernador, Lencinas se preocupó por cumplir con sus compromisos electorales. No nos extenderemos sobre cuestiones económicas, pero señalemos que buscó solucionar los problemas más acuciantes de la vitivinicultura, aquejada

33 En una serie de 1903 a 1914, las tasas comienzan con un 246 por mil y concluyen en el 146 por mil (Anuario de la Dirección General de Estadística de la Provincia de Mendoza correspondiente al año 1914, p. 35).

34 Sobre este período véase RICHARD-JORBA, Rodolfo, Empresarios ricos..., Op. Cit., Capítulo VI.

35 Los menores de 2 años constituyeron el 94\% y el 97\% respectivamente en 1916 y 1925 del total de niños fallecidos por enteritis en esos años.

36 "Manifiesto al pueblo...", Op. Cit., p. 253.

37 Sobre viviendas y condiciones de vida durante el orden conservador, véase RICHARD-JORBA, Rodolfo, Empresarios ricos..., Op. Cit., Cap. VI. 
por crisis recurrentes de sobreproducción y de subconsumo que llevaban varios años. Las leyes 758 y 759, sancionadas en 1919, perseguían la regulación del mercado. La primera, ordenaba la construcción de bodegas regionales con el propósito de que los viñateros sin bodega tuvieran la oportunidad de elaborar su vino sin verse urgidos a malvender la uva a los bodegueros antes de que se produjera su deterioro. En este sentido, había una clara intencionalidad de apoyar a los grupos menos favorecidos de la economía vitivinícola: los viñateros independientes y los trabajadores, es decir sectores medios y populares, porque si se lograba cosechar toda la uva y elaborarla, se tendía a mejorar el ingreso de estos actores y a reducir la desocupación generando nuevos empleos o conservando los existentes.

La ley 759 instituía un seguro agrícola contra heladas y granizo, que dejan inermes a los productores que padecen estos fenómenos. El sistema fracasó rápidamente, tanto por corrupción de los presuntos afectados como por ineficiencias del gobierno. Finalmente, sería derogada durante el gobierno de Carlos W. Lencinas, lo mismo que la ley 758, pese a algún éxito parcial de elaboración de vino por parte de viñateros cooperativizados; pudo más la presión del poder económico local canalizada a través de un movimiento denominado deroguista, que tuvo amplio apoyo social.

\section{La salud pública}

En Mendoza (y en el país ${ }^{38}$ ) no existía, obviamente, el concepto de salud pública que se impondría en el país con el peronismo, considerada parte de un sistema integral de desarrollo económico y social. ${ }^{39} \mathrm{El}$ hospital público era concebido como institución benéfica para atender a los sectores populares y, excepcionalmente, a grupos de mayores niveles de ingreso (por ejemplo, con cirugías). No existían clínicas privadas ni hospitales de comunidades. La medicina preventiva estaba a cargo de la Asistencia Pública, encargada de desinfecciones y campañas de vacunación; también trataba pacientes ambulantes en consultorios externos; en años sucesivos incorporó especialidades médicas que abarcaban un amplio espectro de patologías.

José Néstor Lencinas se propuso extender y mejorar los servicios de asistencia médica a los sectores populares, efectivizando la descentralización geográfica iniciada con los gobiernos conservadores. Desde el momento en que asumió llevó a cabo refacciones en el más antiguo hospital mendocino, el San Antonio; concluyó obras complementarias en el hospital de Maipú -a $15 \mathrm{~km}$ de la capital- (25 camas) y finalizó las del hospital Regional

38 Para tener un buen panorama sobre las instituciones de salud en Buenos Aires, que era la avanzada del país en la materia, véase BELMARTINO, Susana, La atención médica argentina en el siglo XX. Instituciones y procesos, Siglo XXI editores, Buenos Aires, 2005, Capítulos 1 y 2.

39 Véase CARRILLO, Ramón, Contribuciones al conocimiento sanitario, Obras Completas II, EUDEBA, Buenos Aires, 1974. Especialmente "Sentido Justicialista de la Medicina”, p. 144 y "La Salud Pública actual desde el punto de vista peronista”, pp. 339-340. 
de San Martín -50 km al Este- (60 camas) que venían del denostado régimen oligárquico; propuso construir un hospital moderno en la ciudad capital destinado a enfermedades infecto-contagiosas y a la atención de tuberculosos; sugirió crear servicios para atención de enfermedades venéreas, ampliar la atención de niños y fundar un Instituto de Puericultura para educar a las madres. Asimismo, avanzó en los estudios y firma de convenios con Obras Sanitarias de la Nación para la ampliación y difusión geográfica de los servicios de agua y cloacas. ${ }^{40}$ Sin embargo, la situación de la asistencia médica a la población era precaria y la infraestructura, insuficiente, desbordada por una demanda creciente ${ }^{41}$ Tampoco se modificaron concepciones de la Asistencia Pública provenientes del orden conservador, que avanzaban sobre la dignidad de las personas, lo que merecía la crítica desde la prensa opositora. ${ }^{42}$

\section{La vivienda}

Nada se hizo durante el período del Gaucho en materia de vivienda social, pese a los reclamos de la prensa, a las promesas del caudillo hechas en su Manifiesto y a la evidencia de que la creciente población generaba una enorme demanda frente a una oferta que permanecía estancada. Esto daba lugar a la ya mencionada constante suba en el precio de los alquileres que venía, por lo menos, desde comienzos de siglo y se mantenía sin cambios con el gobierno del caudillo radical. El resultado, previsible, era el hacinamiento en conventillos en la ciudad capital (y otros departamentos), agudizando los problemas de falta de higiene y abriendo las puertas para enfermedades y posibles epidemias. ${ }^{43}$ Asimismo, algún

40 Mensaje del gobernador José Néstor Lencinas inaugurando el período legislativo 1918, transcripto en NIETO RIESCO, Julio, José Néstor ... (Jefe de Estado) ..., Op. Cit., pp. 266-275.

41 Por ejemplo el Hospital Provincial, el más grande y complejo, en 1918 tenía 400 camas, todas ocupadas; el San Antonio, 185 y 240 enfermos; y la Casa de Aislamiento 90 camas para 140 enfermos (Mensaje del Gobernador José Néstor Lencinas a la Legislatura, 1918, en NIETO RIESCO, Julio, José Néstor... (Jefe de Estado) ..., Op. Cit., p. 277.

42 Se cuestionaban aspectos centrales: atención médica deficiente, con fallas de diagnósticos y prescripciones incorrectas, así como la obligatoriedad, para ser atendido, de presentar certificado de pobre de solemnidad (El Socialista, 25/07/1920, p. 1). Aunque Lencinas había fallecido, el lencinismo continuaba en el poder y es claro que la Asistencia Pública conservaba prácticas que venían del período anterior.

43 En un artículo titulado "La Salud Pública" se critica fuertemente al gobierno lencinista por no prevenir en la materia, lo mismo que a la Asistencia Pública y la municipalidad capitalina. Los conventillos, entre otros establecimientos, “... constituyen verdaderos focos de infección y agentes propagadores de toda clase de microbios ... Falta de baños, extracción de basuras... se notan... cuando una enfermedad contagiosa hace su aparición..." (El Socialista, 03/11/1918, p. 3). 
fenómeno natural (aluviones) provocaba migraciones internas que agudizaban el problema de la vivienda e, inclusive, daban lugar a actitudes discriminatorias de los propietarios:

En este departamento [Godoy Cruz] puedo decir casi exclusivamente obrero... los gobiernos, o mejor dicho los desgobiernos, no se han preocupado de la habitación para obreros... he tenido que recorrer toda... la Villa buscando casa para alquilar y debido en algo a las recientes crecientes en la parte baja de la ciudad [capital] y el departamento de Las Heras una parte de los habitantes de dicho departamento se han venido a Godoy Cruz, y aquí el que tiene casa o casas para arrendar lo primero que pregunta es: ¿tiene hijos?, y el que conteste sí, no hay casa... así que tendremos que ir a vivir a la intemperie... ${ }^{44}$

Por la información disponible, puede afirmarse que los alquileres representaban, como mínimo, del 20 al 25\% del ingreso de un obrero y superaban ese porcentaje en los de personal no calificado, jornaleros y peones. ${ }^{45} \mathrm{Y}$ el problema se mantendría también $-\mathrm{y}$ recrudecería- en el gobierno del hijo del caudillo. El discurso pro-viviendas obreras había quedado sólo en eso.

Para Rodríguez, finalmente

... en el terreno concreto, la acción de Lencinas desde el gobierno por el mejoramiento de las condiciones de vida de los pobres no fue tan revolucionaria como la propuesta teórica de su legislación social. La situación de pobreza que afectaba a grandes sectores de la población rural y urbana no se modificó en gran medida durante su gobierno.. $.6^{46}$

44 “El problema de la habitación”, El Socialista, 18/05/1919, p. 2. Agrega el diario: “... vivimos no en casas sino en focos infecciosos... ¿Qué hombres sanos y robustos puede tener una nación? Mal comidos, mal vestidos, mal dormidos y teniendo que vivir en chosas (sic)..." Otra interesante nota, típica actitud de docencia de los socialistas, relaciona la tuberculosis y enfermedades que afectaban especialmente a los niños con las condiciones antihigiénicas de las viviendas obreras. Señala, además, que el elevado precio de los alquileres se lleva la mayor parte de las entradas del obrero, particularmente de aquellos que por estacionalidad dejan de trabajar durante un período, El Socialista, 01/06/1919, pp. 2-3.

45 El 25\% lo estima El Socialista, 17/10/1920, p. 1. Otra información confirma el peso de los alquileres en el salario. Un presupuesto de obreros tranviarios (que no eran los peor pagos entre los jornaleros) ascendía a $\$ 118,11$ mensuales; el alquiler insumía $\$ 25$ (21\% del gasto mensual), Los Andes, 30/03/1922. Como referencia más amplia para completar este panorama, entre 1893 y 1905, el alquiler de una habitación costaba \$ 8; en 1927 ascendía a \$ 20 o \$ 40 si se trataba de dos piezas (RICHARD-JORBA, Rodolfo, Empresarios ricos..., Op. Cit., pp. 255 y 256).

46 RODRÍGUEZ, Celso, Lencinas y Cantoni ..., Op. Cit. p. 102. Este autor no estudia la situación social en detalle. 


\section{El gobierno de Carlos Washington Lencinas}

El Gauchito fue elegido gobernador por amplia mayoría de votos y se hizo cargo en febrero de $1922 .{ }^{47}$ Aunque adoptó un discurso menos belicoso que el de su padre, inclinándose por contemporizar y reconocer a los partidos de la oposición, su gestión estuvo signada también por el escaso respeto a las instituciones, el nepotismo y la corrupción. ${ }^{48}$ Una nueva intervención, a cargo de Enrique Mosca en octubre de 1924, le impidió concluir su mandato. En 1926 asumiría el mencionado Alejandro Orfila. Y en medio del fárrago y la violencia políticos, el Gauchito terminaría sus días asesinado en noviembre de 1929, un crimen a todas luces político, que el gobierno yrigoyenista intentó hacer aparecer como pasional. ${ }^{49}$

Los Mensajes de Lencinas (h) a la Legislatura son pródigos en palabras ampulosas, edulcoradas, que recuerdan la memoria del padre y amplifican desmedidamente su obra; y tienden puentes hacia una oposición que no le perdonaba sus errores. Había abandonado el lenguaje agresivo que ayudaba a dividir la sociedad entre categorías dicotómicas (oligarquía/trabajadores; oligarquía/pueblo...), y procuraba, por el contrario, presentarse como un hombre sencillo que sólo buscaba el bienestar general, invocando al diálogo como método eficaz para la solución de las controversias. Así decía en su segundo Mensaje (1923):

Los ciudadanos que ejercen el actual Gobierno... que llevan sobre sí la tarea difícil de cumplir paulatinamente con su apostolado radical de reparación moral, en todos los órdenes de la actividad pública, como en el propio reconocimiento de los humanos derechos del obrero, han de inspirarse en esos sacrificios ... [para lograr] honra ... de este Gobierno ... [y el] bienestar general de la Provincia. ${ }^{50}$

Destacaba que su gestión había logrado superar la crítica situación en que se desenvolvía la vitivinicultura y justificaba el modo en que había cedido frente al poder económico que presionó para la derogación de las leyes que regulaban la actividad, como fuera mencionado.

Colocado el Gobierno en un plano superior de equidistancia pudo graduar... la ponderación indiscutible del movimiento deroguista y... llegó al convencimiento de la necesidad de ceder a sus exigencias, convencido, como está de que un Gobierno de opinión es no sólo aquel que consigue atraer el mayor número de voluntades sino el que sabe responder... a

47 El partido se había escindido y Lencinas fue llevado al triunfo por la Unión Cívica Radical Lencinista, que adheriría al antipersonalismo en el orden nacional.

48 RODRÍGUEZ, Celso, Lencinas y Cantoni ..., Op. Cit.

49 Ibídem.

50 Mensaje del Gobernador de la Provincia de Mendoza Dr. Carlos Washington Lencinas Leído ante la Asamblea Legislativa al inaugurarse el período, 1 de junio de 1923, Imp. Italia, Mendoza, 1923, p. s/n. 
las corrientes elevadas de esa misma opinión en demanda vehemente de lo que considera sus legítimos intereses.

La actitud del Gobierno fue tanto más levantada y generosa si se piensa que sus vistas eran diametralmente opuestas a las sintetizadas por la opinión deroguista... Por imperio de las leyes sancionadas la industria vitivinícola recobra su amplia libertad de acción al desaparecer las trabas que creaban leyes anteriores... [aunque advierte a bodegueros y viñateros que de allí en más quedarán sujetos a los] azares de una suerte variable. ${ }^{51}$

En suma, en este aspecto central, Lencinas cedía, abandonaba el enfrentamiento de su padre con el poder económico y sus firmes posiciones intervencionistas dejando a la vitivinicultura librada a la mano invisible del mercado. El gobierno, que había logrado, desde 1922, reactivar la actividad vitivinícola y recuperar su rentabilidad gracias a medidas intervencionistas, había arriado sus banderas. Y el liberalismo tan vilipendiado volvía por sus fueros. Para completar ese retroceso, se sancionó la ley 866, en 1923, que restauró el impuesto a la uva para elaborar vino fuera de la provincia, "lo que obligó a los viñateros a vender su producción a los bodegueros de Mendoza." ${ }^{52}$

En el Mensaje de 1924, Lencinas sólo expresa unas palabras sobre la cuestión social atribuyéndose creaciones que se originaron en la gestión paterna, aunque comenzaban a llevarse a la práctica durante su gobierno. Suya era, en cambio, la creación de la Caja Obrera de Pensión a la Vejez e Invalidez (Ley 854, de 1923), cuestionada por la prensa desde que estaba en proyecto. ${ }^{53}$ Ese cuestionamiento, al menos en parte, tenía que ver con los recursos para pagar las pensiones ${ }^{54}$ y Lencinas lo ponía en claro:

Desde luego han quedado descartados los sistemas que han pretendido basarse en la contribución pecuniaria del mismo obrero, por cuanto éste, con su natural imprevisión,

51 Ibídem. Es decir, Lencinas abandonaba el pensamiento y la acción de su padre en el sentido de que el Estado debía intervenir activamente en la economía y regular la principal actividad de la provincia, la vitivinicultura, sujeta a vaivenes que la hacían recaer permanentemente en crisis de variada intensidad. Con la derogación de las leyes reguladoras, todo volvía a estar sujeto al libre juego de la oferta y la demanda. Se restablecía así la profunda relación de dependencia de los viñateros independientes respecto de los bodegueros.

52 RODRÍGUEZ, Celso, Lencinas y Cantoni..., Op. Cit., p. 178, Nota 15.

$53 \mathrm{El}$ diario Los Andes cuestionaba que el proyecto no hubiera sido debidamente estudiado y acusaba al gobierno de legislar, como en ocasiones anteriores, "con un propósito ostensiblemente electoralista", Los Andes, 27/12/1922, p. 5.

$54 \mathrm{La}$ ley creaba un impuesto mensual de $\$ 0,50$ por cada persona empleada del sector público, empresas o particulares que no estuviera protegida por un régimen jubilatorio; una tasa progresiva sobre el valor de las propiedades inmuebles y otro impuesto sobre los inmuebles rurales con derecho de riego que no estuvieran cultivados. Estas imposiciones explican la reacción negativa de la prensa. 
y con sus reducidos recursos, no está por lo común dispuesto, ni preparado para el ahorro ni para pensar en el futuro lejano... 55

Esta cita es importante porque, pese al discurso obrerista, descubre la concepción que tenían Lencinas y su grupo dirigente de los trabajadores, casi como seres incapaces de prever algo más allá del día a día; pero, además, y creemos más destacable, es el reconocimiento del muy reducido ingreso obrero que, al parecer, no había mejorado durante la gestión del lencinismo. Precisamente el diario Los Andes apuntaba que las leyes de protección social sancionadas durante el gobierno del padre eran ineficaces en su aplicación. ${ }^{56} \mathrm{La}$ improvisación parecía primar: a la Caja, durante 1924, sólo se le había asignado un local provisorio y comenzaba su organización administrativa. No obstante, en su Mensaje el gobernador hablaba de atender a la "clase proletaria" y de cumplir con sus promesas electorales "... de mejoramiento para la clase obrera, que en reiteradas ocasiones y desde el llano hiciera al pueblo..." 57

No obstante, Lencinas (h) se preocupó por poner en marcha el Departamento Provincial del Trabajo que, durante un año y medio no había hecho inspecciones, ni en la Capital ${ }^{58}$ ni, por supuesto, en los departamentos, de manera que sólo era una oficina que acumulaba expedientes de reclamos, mientras las patronales pasaban por alto la jornada de $8 \mathrm{hs}$. establecida por la ley 732, considerada ineficaz por el diario Los Andes, como ya mencionáramos. Sin embargo, entre marzo y junio de 1922 se hicieron casi 700 inspecciones, tanto para hacer cumplir las leyes de descanso dominical, las de trabajo de mujeres y menores y la de jornada máxima, como para verificar instalaciones y prevenir accidentes laborales, ${ }^{59}$ todo lo cual era un significativo avance social. Y, por primera vez, se habían enviado inspectores a diversos departamentos de la provincia “... donde se ha comprobado el incumplimiento de las leyes en vigencia". ${ }^{60}$ El año siguiente el Departamento de Trabajo amplió su accionar, instalando oficinas de inspección permanentes en San Rafael (Oasis Sur), San Martín,

55 Mensaje del Gobernador de la Provincia de Mendoza Dr. Carlos Washington Lencinas Leído ante la Asamblea Legislativa al inaugurarse el período, 7 de junio de 1924, Imp. Italia, Mendoza, 1924, Apartado Ministerio de Gobierno-Caja Obrera de Pensión a la Vejez e Invalidez, p. s/n. Resaltado nuestro.

56 Los Andes, 27/12/1922, p. 5

57 Mensaje del Gobernador... 1924, Op. Cit. Apartado Ministerio de Gobierno.

58 Mensaje del Gobernador de la Provincia de Mendoza Dr. Carlos Washington Lencinas Leído ante la Asamblea Legislativa al inaugurarse el período, 1 de junio de 1922, Talleres Gráficos de la Escuela Alberdi, Mendoza,1922, p. 29. La oficina tenía 6 inspectores, de los que trabajaban sólo dos, según el gobernador.

59 Ibídem, p. 29. Los inspectores llegaron a clausurar 11 calderas.

60 Ibídem. 
Luján y Tunuyán, con lo cual se podía abarcar toda la provincia. ${ }^{61} \mathrm{Y}$ si bien estas acciones mostrarían una voluntad política para hacer cumplir las leyes, no hay información sobre cantidad de inspecciones, infracciones detectadas y multas aplicadas, lo que hace pensar que el Departamento no resultaba del todo eficaz, aunque sin dudas era un buen comienzo, ${ }^{62}$ teniendo en cuenta que en otras zonas del país apenas se discutía sobre la conveniencia de crear un Departamento de Trabajo. ${ }^{63}$

\section{La salud pública}

Este fue tal vez el campo donde el Gauchito desplegó sus mayores anhelos. Así lo expresaba: “[...] yo creo que parodiando (sic) a Alberdi, podríamos afirmar con honda convicción el apotecma (sic) de que para Mendoza, en primer término, gobernar es afianzar la salubridad pública..." ${ }^{94}$ En 1922 hizo una considerable ampliación del presupuesto ${ }^{65}$ destinado a salud pública, de más de un millón de pesos. Al igual que su padre, extendió servicios asistenciales a los departamentos y amplió el número de camas para internación. En 1923-1924 se crearon servicios diversos en los hospitales Provincial y San Antonio, también un instituto de bacteriología y laboratorio de anatomía patológica, salas de primeros auxilios en los departamentos, ampliación de la Asistencia Pública, con servicios de pediatría, clínica médica, ginecología y obstetricia, etc. La creación de la Cantina Maternal y Dispensario de Lactantes abrió una nueva etapa cualitativa (julio de 1924) en la que el Estado asumía el apoyo alimentario a las madres necesitadas, el seguimiento de la evolución

61 Mensaje del Gobernador de la Provincia de Mendoza Dr. Carlos Washington Lencinas Leído ante la Asamblea Legislativa al inaugurarse el período, 1 de junio de 1923, Imp. Italia, Mendoza, 1923, p. s/n. Apartado Ministerio de Gobierno.

62 Por ejemplo, se creó un registro de trabajadores menores de ambos sexos y entre el 7 de febrero y el 30 de mayo de 1922, se habían inscripto 366 menores (246 varones y 120 mujeres), que habían sido habilitados para trabajar (Mensaje del Gobernador... 1922, Op. Cit., p. 31.).

63 Véase ULIANA, Hernán A., "El Congreso del Trabajo de 1923 y la complejidad en la construcción de las ideas", en BONAUDO Marta S. (directora), Imaginarios y prácticas de un orden burgués. Rosario, 1850-1930, Tomo II - Instituciones, conflictos e identidades, Prohistoria Ediciones, Rosario, 2010, pp. 139-164.

64 Del discurso pronunciado por Carlos W. Lencinas en la inauguración de las obras de construcción de la red cloacal de la ciudad de Mendoza, noviembre de 1923 (La Provincia de Mendoza durante el Gobierno del Dr. Carlos Washington Lencinas, en Páginas Argentinas. Revista mensual ilustrada, Número extraordinario, Buenos Aires, junio de 1924, p. s/n.

65 Era el mismo presupuesto de 1916 prorrogado sucesivamente. 
de los lactantes y, algo fundamental, la enseñanza de normas de higiene personal, de los niños y sobre manipulación y preparación de alimentos. ${ }^{66}$

La terminación del Hospital de San Rafael fue otro hito destacable; lo mismo que la del Hospital José Néstor Lencinas, especializado en enfermedades infecto-contagiosas y tuberculosis, como ya fuera expresado. Ambos establecimientos se libraron al servicio en 1924. El antiguo Lazareto fue transformado en hospital de crónicos, con el nombre de Luis C. Lagomaggiore, teniendo como misión actuar complementariamente con el Lencinas. Es decir que se aplicaba una verdadera concepción de la salud pública con atención primaria en los consultorios de la Asistencia Pública en la Capital y Salas de Primeros Auxilios en los departamentos; y, aumentando la especificidad, se apelaba primero a los Hospitales Regionales (San Martín, Maipú, San Rafael) y luego a los especializados o con equipamiento más complejo (Provincial, San Antonio, José Néstor Lencinas o El Carmen).

Como parte de esa concepción amplia de la salud de la población, y continuando lo emprendido por su padre, Carlos Washington Lencinas concluyó gestiones ante el gobierno nacional para que Obras Sanitarias ampliara la red de agua potable para la ciudad de Mendoza $^{67}$ y la construyera en las villas más importantes de la provincia (San Rafael, San Martín, Junín, Rivadavia, Alvear y Pueblo Luna); y para la construcción de la red cloacal en la ciudad capital. ${ }^{68}$ Las obras cloacales, que demandarían 5 años, fueron comenzadas en noviembre de $1923 .{ }^{69}$ Sin embargo, resulta evidente que el gobierno provincial hizo su parte con mucha lentitud, lo que entorpecía el inicio de los trabajos; y esto era severamente cuestionado por la prensa, ${ }^{70}$ que no sólo remarcaba la imperiosa necesidad de que la ciudad

66 La institución, instalada en la capital, funcionó desde julio de 1924 y fue inaugurada oficialmente el 4 de agosto por el gobernador Carlos W. Lencinas y el Director de Salubridad, Dr. Bernabé Ferreyra. El programa contemplaba extender estas Cantinas; y contaría, además, con el apoyo de la Beneficencia privada, que aportaría una "sala-cuna en la capital", Los Andes, 05/08/1924, p. 5. En una publicación de junio, Ferreyra anunciaba la próxima inauguración de la Cantina y explicaba que se había inspirado en sus similares de Capital Federal, recordando a su "entusiasta iniciadora y a la vez que organizadora...", Sra. Elena Acevedo de Martínez de Hoz, Los Andes, 20/06/1914, p. 5.

67 A fines de 1924, varios barrios de la ciudad de Mendoza no contaban con servicio de agua potable (Paginas Argentinas..., Op. Cit., p. s/n.).

68 Con estas obras Mendoza adoptaba tardíamente las concepciones higienistas vigentes en el país desde fines del siglo XIX y comienzos del XX. Véase al respecto SURIANO, Juan (compilador), $L a$ cuestión social en la Argentina, 1870-1943, Editorial La Colmena, Buenos Aires, 2004. Del propio Suriano, véase su trabajo "Introducción: una aproximación a la definición de la cuestión social en la Argentina"; también el capítulo específico de ARMUS, Diego, "Consenso, conflicto y liderazgo en la lucha contra la tuberculosis. Buenos Aires 1870-1950".

69 Mensaje del Gobernador... 1924. Apartado Ministerio de Industria y Obras Públicas. Obras Sanitarias.

70 Los Andes, del 16 al 20/02/1923, publicó notas y entrevistas al subsecretario de Obras Públicas 
capital contara con una red de eliminación de excretas, sino que esas obras, por su magnitud, dinamizarían la economía local y contribuirían a reducir la desocupación. Cuestión esta que estaría indicando que el proclamado auge vitivinícola comenzado con el gobierno de Carlos Washington no derramaba sobre el mundo del trabajo y que se mantenían niveles de desocupación elevados, ${ }^{71}$ agravados por la estacionalidad de la agroindustria. Este es un tema que necesita mayores evidencias que surgirán de investigaciones en el futuro, pero los indicios sirven para considerar que pese al voluntarismo oficial, las condiciones de vida de los sectores populares permanecían dentro de grandes franjas de precariedad.

\section{La vivienda}

En la cuestión de las viviendas para los sectores populares resultaban convergentes dos graves problemas: la escasa cantidad y la baja calidad de las mismas. Ellos potenciaban otros dos problemas, que agravaban las condiciones de vida de los sectores populares; uno, económico, representado por el constante aumentos del precio de los alquileres, que absorbía parte considerable del ingreso de los trabajadores; ${ }^{72}$ el otro, se vinculaba con el hacinamiento y la escasez o ausencia de higiene en las unidades habitadas. Menor disponibilidad de dinero significaba sin duda déficit alimentarios importantes y mayor debilidad de las personas; sumado aquello a una obligada menor higiene, daba paso a enfermedades de todo tipo, especialmente las que afectaban a los niños (aparatos digestivo y respiratorio), sobre las que ampliaremos en otro apartado, y a la temida tuberculosis.

En este sentido, el gobierno del Gauchito no tuvo política de vivienda para obreros pese a ser una cuestión reclamada largamente por los gremios, ya desde el período conservador ${ }^{73}$ y apoyada por la prensa opositora y la no partidista desde el comienzo de los gobiernos lencinistas que advertían sobre la escasez y mala calidad de las viviendas. ${ }^{74}$ Éstos ignoraron,

de la Nación, en las que se destacaba que las obras cloacales no comenzaban porque la provincia aún no sancionaba la ley de donación de terrenos para el desagüe de la red.

71 "Desde el punto de vista económico, la instalación de cloacas no resultará menos interesante. Los trabajos ... movilizarían más de un millar de obreros, vale decir que el problema de la desocupación quedaría casi resuelto...", Los Andes, 16/03/1922, p. 5.

72 Véase Nota 44; también las referencias de artículos de prensa ya mencionados que al pedir políticas de vivienda resaltaban el constante incremento de los alquileres por escasez de oferta.

73 Véase RICHARD-JORBA, Rodolfo, Empresarios ricos y..., Op. Cit., Capítulo V. Cabe agregar que la ley 531, sancionada por los gobiernos conservadores, creó el Banco de Préstamos y Ahorros para efectuar préstamos sobre sueldos a empleados públicos y pignoración de joyas y otros objetos. En la gestión del Gauchito se planeaba prestar para la construcción de viviendas económicas, pero no tenemos hasta el momento información de que tales propósitos se hayan concretado.

74 Véase, por ejemplo, El Socialista, 03/11/1918, p. 3; 18/05/1919, p. 2; 01/06/1919, p. 2; 10 y 17/10/1920, p. 1 ; Los Andes, 16/02/1922, p. 5; 10/12/1922, p. 5;21/12/1922, p. $5 ; 18 / 02 / 1923$, p. 5 , etc. 
asimismo, sus propias promesas en la materia. Al momento de asumir Carlos W. Lencinas como gobernador, el problema de la vivienda resultaba acuciante no sólo para los sectores populares, sino también para empleados y estratos medios de la sociedad. ${ }^{75} \mathrm{Y}$ la ausencia de higiene en amplios sectores sociales llevó a dos concejales capitalinos a presentar un proyecto de ordenanza para la construcción de seis casas de baños para obreros en diferentes barrios, las que deberían estar dotadas de agua fría y caliente, a un precio no superior a 10 centavos por el servicio. ${ }^{76}$

Es decir que la principal base social del lencinismo no recibió beneficios para mejorar sus condiciones de vida en el plano de la vivienda, situación que colocaba a los sectores populares en un camino casi circular que realimentaba todos sus déficit: mala vivienda y muy cara, falta de higiene, hacinamiento, deficiente alimentación y enfermedades como conclusión de aquel camino. Y en esa base incluimos a los rechazados del servicio militar, una generación a punto de comenzar la reproducción desde malas condiciones de salud y, seguramente, con serias carencias cognitivas derivadas de una nutrición temprana insuficiente, ${ }^{77}$ lo que se transformaba en un condicionante cultural no menor a la hora de desarrollar políticas de mejoramiento social. Piénsese solamente en qué posibilidades de ascenso social podía tener una persona con estas carencias. Todo indicaría que estaban condenadas a no superar la escala de peones y sobrevivir en la precariedad laboral, fuera por la estacionalidad de la dominante agroindustria vitivinícola, fuera por la presión de la oferta de mano de obra.

75 "El obrero, el empleado y la clase media viven angustiados por el arrendamiento caro y las pésimas condiciones de las modestas habitaciones que ocupan, hasta el extremo de que millares de obreros viven en esta capital en el hacinamiento antihigiénico de los conventillos, Los Andes, 16/02/1922, p. 5. El mismo diario informaba la existencia de no menos de 150 conventillos registrados en la municipalidad de la Capital, a los que agregaba otros cien no inscriptos como tales, Los Andes, 17/03/1922, p. 5

76 Los Andes, 17/09/1922, p. 5. Algunos baños fueron construidos en la ciudad, aunque ignoramos por ahora en qué momento. Uno de ellos, situado en la actual esquina céntrica de avenidas J.V.Zapata y San Juan, funcionó hasta la década de 1960.

77 El efecto de arrastre de las pésimas condiciones de vida de los sectores populares que venían del régimen oligárquico se manifestó escandalosamente a principios de 1923, cuando se dio a conocer que el 71\% (!!!) de los jóvenes convocados para el servicio militar fueron "declarados inútiles por sufrir enfermedades de diversa índole”, Los Andes, 20/02/1923, p. 3. El Gauchito, por ignorancia o por manejo político, se evadía del problema con un atajo discursivo muy simplista, atribuyendo al sedentarismo de los niños y la falta de ejercicios físicos en las escuelas la causa del rechazo; y todo era fruto "de este descuido de nuestros antecesores, pues el bochornoso porcentaje de desechados ..., nos prueba concluyentemente la decadencia de nuestra juventud y nos pone... el deber patriótico de propender al mejoramiento de nuestra raza y ello ha de conseguirse principalmente por la ejercitación física y por las prácticas higiénicas que las mismas traen aparejadas." (Mensaje del Gobernador... 1924, Op. Cit. Apartado Dirección General de Escuelas - Acción Técnica Escolar). 


\section{Los niños, los más castigados por la enfermedad}

En este apartado hemos cuantificado en diversos cuadros los aspectos más importantes para relacionar lo tratado precedentemente y evaluar si las gestiones de los gobiernos lencinistas mejoraron o no las condiciones de vida de los sectores populares.

Aunque en la elaboración de los cuadros hemos apuntado sobre todo a la mortalidad infantil y la de niños menores de 5 años porque constituyen las franjas más vulnerables de la sociedad, hemos incluido información que contribuye a formar una percepción de aquellas gestiones gubernativas regeneradoras, pero también hemos incorporado puntos de comparación con sus predecesoras del orden conservador.

En el Cuadro $\mathrm{N}^{\circ} 1$ hemos construido información a lo largo de una década entre fines del período conservador y los gobiernos de los Lencinas, incluyendo las defunciones producidas por grupos etarios, la evolución de la población total, de la tasa bruta de mortalidad y del porcentaje de menores de un año fallecidos en relación a la población total de la provincia. Todas las cifras confirman tendencias descendentes en la década, tanto en valores absolutos en cada uno de los ítems considerados como en las tasas calculadas. ${ }^{78}$ El Gráfico $\mathrm{N}^{\circ} 1$, elaborado sobre la base del Cuadro precedente, revela claramente una tendencia sostenida a la baja de la tasa bruta de mortalidad; y si se toman los extremos del período, el descenso -significativo- alcanza casi el $22 \%$, como ya expresáramos. Aunque no puede ser monocausal, sí consideramos que tuvo un papel central el mejoramiento de la atención médico-asistencial y las acciones de medicina preventiva adoptadas por el lencinismo, aun cuando merecieran críticas de la prensa. ${ }^{79}$ Lo mismo sucede con la relación porcentual entre los menores de

78 En las décadas de 1870 y 1880 las tasas de mortalidad general urbanas eran muy elevadas, de hasta el 50 por mil y luego comenzaron a descender prácticamente a la mitad o menos, debido en gran medida a la disminución de la mortalidad infectocontagiosa (ARMUS, Diego, "El descubrimiento de la enfermedad como problema social”, en LOBATO, Mirta Z. (directora de tomo), El progreso, la modernización y sus límites (1880-1916), T. V, Nueva Historia Argentina, Editorial Sudamericana, Buenos Aires, 2000, p. 518. En coincidencia con lo que dice Armus, en Mendoza, la tasa bruta de mortalidad en la capital entre 1885 y 1895 fue del 47,5 por mil; en 1910 (total provincial) ya era del 29,4 y en 1914 llegó al 22 por mil (RICHARD-JORBA, Rodolfo, Empresarios ricos..., Op. Cit., Cap. VI, Cuadro VI-\%, p. 275).

79 A las ya citadas al comienzo, agregaremos otras, pequeña muestra de un amplio universo. El Dr. Lucio Funes, prestigioso médico y dirigente político conservador evaluaba en un artículo que la disminución de muertes por tuberculosis en 1920 indicaba un mejoramiento de las condiciones de salubridad e higiene y una mayor difusión de medidas de previsión y profilaxis. Señalaba no obstante, que el gobierno debería hacer hincapié en reducir el extraordinario número de nacidos-muertos "que fallecen por vicios de conformación o debilidad congénita, cuya causa inmediata - en la generalidad de los casos- es la avariosis, enfermedad cuya difusión en todas las clases sociales toma un incremento alarmante...", Los Andes, 01/01/1922, p. 13. La avariosis era el nombre elegante con el que se aludía a la sífilis. Otros artículos señalaban, en 1922, que crecían las muertes por tuberculosis, originada en 
un año fallecidos y la población total de la provincia, que registra un descenso del 33,8 \% en el marco de un fuerte aumento demográfico. Estas tendencias deben ser resultado de la convergencia de diversos factores, aunque esencialmente de la mejor oferta de servicios sanitarios, tanto de los médico-asistenciales como los de medicina preventiva (sin perjuicio de serias fallas ${ }^{80}$ ) y de higiene pública. La mayor cantidad y complejidad de estos servicios, así como su distribución geográfica (que rompía una tradicional concentración en la capital) debió jugar un papel central en la baja de los valores considerados. Una cuestión que deberá ser investigada es determinar si entre las causas de los descensos apuntados podrían considerarse los efectos de la transición demográfica ${ }^{81}$ tema que escapa a los objetivos que nos hemos planteado en este artículo. Agreguemos que por el lado de los ingresos, la mayor parte de los trabajadores, integrantes del sector privado, habrían experimentado aumentos en sus salarios ( jornales de $\$ 2$ en 1918 a $\$ 3$ desde 1919 para los peones), lo que habría redundado en mayores posibilidades de mejorar su alimentación y vivienda. Aunque esos incrementos deberán ser confirmados, es oportuno señalar, además, que no tuvieron variaciones al menos hasta $1927 .{ }^{82}$

el pauperismo y la mala alimentación e instaban al gobierno a alimentar bien al pueblo, Los Andes, 15/02/1922; o destacaban las deficiencias hospitalarias que llegaban a extremos tales como que las camas de maternidad del Hospital Provincial eran ocupadas por dos parturientas simultáneamente y otras eran rechazadas por imposibilidad de ser internadas, Los Andes, 21/12/1922, p. 5. En fin, una fuerte crítica, frente al incremento de enfermos tuberculosos, muchos de los cuales venían de otras provincias, se hizo a la decisión del gobierno de habilitar el Hospital José N. Lencinas, cuando se inaugurara, para atención de enfermos generales dejando sólo un pabellón para enfermedades infecto-contagiosas, Los Andes, 28/10/1923, p. 5. Y el diario adoptaba un discurso virulento y racista porque como había numerosos casos de tuberculosos de origen inmigratorio, aumentaba el número de víctimas “... influyendo desastrosamente sobre la economía de la familia, del pueblo y del Estado y amenazando la nacionalidad"; exigía, entonces, que el nuevo hospital se destinara exclusivamente a los casos de tuberculosis y otras enfermedades infecto contagiosas: "Con eso el gobierno habría cumplido una alta misión humanitaria y nacionalista".

80 Esto quedó manifiesto en el importante brote de viruela que se desató en la capital en 1923, con varios muertos. El gobierno no disponía de suficientes vacunas y el Departamento Nacional de Higiene no las proveyó en las cantidades necesarias, lo que dificultó enormemente la vacunación y revacunación de la población afectada, tornando ineficaces otras medidas sanitarias para controlar la difusión de la enfermedad. Véase por ejemplo Los Andes 03/03/1923 y 07/03/1923.

81 Muy ilustrativo es un libro de BOLSI, Alfredo, ORTIZ de D'ARTERIO, Patricia, Población y azúcar en el Noroeste Argentino. Mortalidad infantil y transición demográfica durante el siglo XX, UNTucumán, Tucumán, 2001. Para Mendoza, véase la obra de CERDÁ, Juan Manuel, Condiciones de vida y vitivinicultura. Mendoza, 1870-1950, UNQuilmes, Bernal, 2011, Cap. V. El autor destaca allí características que diferenciarían a la provincia de los modelos de transición propuestos para la Argentina.

82 Véase ZULOAGA, Manuel A., Salario mínimo..., Op. Cit., p. 60. Esta fuente, como ya expresá- 
El Cuadro $\mathrm{N}^{\mathrm{o}} 2$ es también elocuente y muestra las tasas de mortalidad infantil en una clara, aunque suave, tendencia descendente $(5,25 \%$ menos) si tomamos como base 1914 , que tuvo una tasa anómala en el contexto de la época; o, más importante, 21,7\% menos si consideramos la década analizada en este trabajo. En este aspecto, sin duda, debieron tener incidencia la docencia con las madres en el consultorio de puericultura, los servicios de pediatría y sala de lactantes en hospitales y Asistencia Pública, los de análisis clínicos y bacteriológicos, creados entre 1923 y 1924 , el servicio de ambulancias ${ }^{83}$ así como la asistencia alimentaria, implementada para familias muy carenciadas en el transcurso de $1924^{84}$ y que estuvo plenamente operativa en $1925,{ }^{85}$ entre otras acciones. Es decir que, objetivamente, y al margen de errores, deficiencias y críticas, hubo asistencia directa a los sectores populares que redundó en mejoras de sus condiciones de salud y eso se refleja en las tasas que hemos registrado.

El Cuadro $\mathrm{N}^{\circ} 3$ muestra otra faceta de la problemática de la salud. Hemos incluido allí las causas de defunción de niños menores de 5 años, la franja etaria más vulnerable y más castigada. Se podría comentar mucho, pero señalaremos sólo algunas observaciones. En primer lugar, raquitismo y hambre, dos causas estrechamente relacionadas, fueron numéricamente escasas y marcaron una tendencia porcentual descendente, lo que indicaría mejores condiciones de atención de la niñez y, también, de acceso a los alimentos. Sin embargo, estas causas también pueden relacionarse con "Vicios de conformación congénitos" y "Debilidad congénita", cuyas tasas se mantuvieron en el período relativamente estables en el primer caso y aumentaron significativamente en el segundo (123,5\%). En ambos casos hemos visto que el Dr. Lucio Funes atribuía gran parte de estas muertes a la avariosis (sífilis), enfermedad

ramos, no aporta evidencia de que los obreros alcanzaran en 1919 el jornal de 3 pesos. Posiblemente se trate de un promedio, con lo cual habría muchos por debajo del mismo o bien, que sólo se tratara de una expresión propagandística. El mismo documento -recordemos que es de 1927- tiene contradicciones, porque en la p. 19, el Mensaje del proyecto de ley para aumentar salarios dice que aún estaban vigentes los $\$ 2,50$ para estatales y $\$ 2$ para privados establecidos por ley 732 . No tenemos hasta ahora evidencia documental de que los jornales mínimos estuvieran por encima de estos valores. 83 Por ejemplo, en 1924, el denominado tren de ambulancias trasladó a hospitales 4.601 enfermos; en 1925 fueron 4.197 (Anuario de la Dirección General de Estadística de la Provincia de Mendoza correspondiente al año 1924, Buenos Aires, 1925, p. 426; y Anuario... 1925, Buenos Aires, 1926, p. 324).

84 Mensaje del Gobernador... 1924. Apartado Ministerio de Industria y Obras Públicas. Dirección General de Salubridad.

85 En 1925, además de los servicios en hospitales, el Consultorio de Lactantes atendió 8.616 niños (3.613 ya inscriptos y 5.003 nuevos); el Consultorio Obstétrico examinó 479 mujeres, atendió 65 partos y realizó 225 visitas domiciliarias; la Sala de Puericultura atendió 1.411 mujeres. En el Comedor de la Cantina Maternal, por su parte, 445 niños retiraron alimentos preparados (Anuario... 1925, Op. Cit., p. 325). 
que experimentaba un crecimiento fuerte y constante en los casos fatales $(237,5 \%)$, lo que evidencia fallas graves en la prevención y en el control de su difusión. La sífilis también se expande en condiciones de higiene precarias, por lo que su aumento es un indicio de que las condiciones de vida de los sectores populares -especialmente el hábitat-, no registraban mejoras dignas de mención. Finalmente, las defunciones por enfermedades gastrointestinales, el gran flagelo de los niños, y las del aparato respiratorio, se mantuvieron estables o con ligeras bajas. ${ }^{86}$ Esto es otro fuerte indicio de que la manipulación de alimentos, las condiciones de muy baja calidad de la vivienda, la ausencia de servicios de agua corriente y cloacas y otros factores resultaban determinantes para el mantenimiento de unas tasas que no diferían significativamente de las registradas en el período conservador, caracterizado por las mismas deficiencias habitacionales y sanitarias. ${ }^{87}$ En este aspecto, podría pensarse que los gobiernos lencinistas fueron inoperantes; sin embargo, debe tenerse en cuenta que el crecimiento demográfico fue importante y las defunciones consideradas en valores absolutos disminuyeron claramente y, como vimos en el Gráfico $\mathrm{N}^{\circ} 1$, también descendieron las tasas; y es en esa disminución en la cantidad de decesos donde sin duda hay un positivo resultado de las políticas del lencinismo.

Finalmente, el Cuadro $\mathrm{N}^{\circ} 4$ nos acerca a otros indicios probatorios del accionar de los gobiernos lencinistas a favor de los sectores populares. En efecto, a la menor cantidad de decesos debe agregársele el lugar en que ocurrieron; y en este sentido, los fallecimientos en conventillos cayeron un $89 \%$ en los extremos de la década considerada y en un 4,25\% aumentaron los ocurridos en hospitales. Estas cifras confirman una preocupación por atender a los grupos más carenciados, radicados en conventillos, que fueron trasladados e internados en hospitales. Es decir, mejoró la cobertura médico-asistencial pese a una notoria difusión geográfica de los conventillos. ${ }^{88}$ La cantidad de fallecidos en la vía pública no tiene peso estadístico y no permite hacer suposiciones convincentes.

86 Para las enfermedades "gastrointestinales y la tuberculosis no hubo vacunas eficaces ni las obras de salubridad fueron capaces de alterar las tendencias de la normalidad que estas enfermedades acarreaban desde el último tercio del siglo XIX" (ARMUS, Diego, "Consenso, conflicto...", Op. Cit., p. 194). Situación descripta para Buenos Aires que era un calco, tal vez multiplicado, de lo que ocurría en Mendoza.

87 Véase RICHARD-JORBA, Rodolfo, Empresarios ricos..., Op. Cit., Capítulo VI, Cuadro VI-6, p. 276.

88 Aunque no ha sido incluida en el Cuadro No 4, los Anuarios Estadísticos de 1923 a 1925 traen información desagregada del lugar de ocurrencia de los fallecimientos. Esto permite conocer que ya existían conventillos, además de la ciudad capital, en los departamentos de Godoy Cruz, Guaymallén, Las Heras y Luján (hoy reunidos en el Gran Mendoza) y otros más alejados (Rivadavia, San Martín, La Paz y San Rafael), de modo que las precarias condiciones de vivienda e higiene se extendían a la mayor parte del territorio provincial. 


\section{Conclusiones para avanzar en la reconstrucción buscada}

José Néstor Lencinas intentó cumplir las promesas electorales y buscó una transformación tendiente a promover el ascenso social de los sectores populares, pero por diversas circunstancias el proyecto quedó en gran medida trunco. Tal vez porque el jefe radical perdió el apoyo de Yrigoyen y fue intervenido federalmente; una vez repuesto en el cargo, murió un año antes de cumplir su mandato. Es decir, a las intermitencias de la gestión se sumó la muerte del caudillo para frenar sus proyectos.

Sin embargo, avanzó en la concreción de una legislación social de avanzada en Mendoza y en el país. La jornada máxima de 8 hs., el salario mínimo -aunque sólo aplicable al sector público-, las Cajas de Jubilaciones y Pensiones de la Provincia, junto con la creación de la Inspección General de Trabajo, fueron generando una institucionalidad diferente, en la que el Estado pasaba a tener injerencia en las relaciones laborales, en los contratos de trabajo y actuar como mediador de los conflictos. Parte de esta legislación la pondría en marcha su hijo, pero la aplicación, aunque fuera parcial, de las jornadas máximas y los salarios mínimos, sin duda debió mejorar las condiciones de vida de una parte (menor) del mundo de los trabajadores, sirviendo de cimiento para un tipo de construcción de protección social que debía romper medio siglo de liberalismo. Complementariamente, el Gaucho avanzaría en una ampliación y descentralización de los servicios médico-asistenciales y de obras sanitarias, cuestión esencial si realmente se piensa en la elevación de los sectores populares a niveles mínimos compatibles con la dignidad humana.

Carlos Washington siguió parcialmente el legado de su padre. Atemperó el discurso agresivo, pero mantuvo condiciones de baja calidad institucional. La legislación sobre vitivinicultura sancionada durante el gobierno de su padre fue utilizada para sacar a la agroindustria de la crisis y ponerla nuevamente en camino del crecimiento. No obstante, cedió ante el poder económico, derogó esas normas y se volvió a la ley de la oferta y la demanda, a la plena vigencia de la mano invisible del mercado.

En lo social, el discurso obrerista, caro a los oídos populares, se mantuvo, pero no avanzó en la aplicación de la legislación que hubiera obligado al sector privado a pagar los salarios mínimos, es decir, nunca reglamentó (al igual que su padre), el artículo de la ley 732 que establecía esos ingresos. Sin embargo, puso en marcha el Departamento de Trabajo y comenzó las inspecciones en toda la provincia, una forma de presión sobre las patronales para que se ajustaran a la ley de jornada máxima, de trabajo de menores y mujeres, seguridad e higiene, etc. También comenzó la organización de la pensión de la vejez e invalidez y durante su gestión comenzarían los primeros pagos de jubilaciones de trabajadores estatales.

Debe reconocérsele, además, la creación y ampliación de servicios médico-asistenciales en toda la provincia y el diseño implícito de una planificación de la atención de la salud para los sectores populares y de asistencia alimentaria para madres y niños lactantes. Junto con esa política, la construcción de redes de agua potable y de cloacas deberían completar las condiciones básicas para asegurar la salud de la población y bajar las altísimas tasas de 
mortalidad infantil que agobiaban a la provincia. No obstante, durante gobierno de Lencinas (h), las enfermedades gastrointestinales y otras vinculadas con la ausencia de higiene y mala alimentación seguían siendo la principal causa de mortalidad infantil. Este es un indicador de que las condiciones de vida de la base social del lencinismo, los sectores populares, no se habrían modificado sustancialmente respecto de las existentes en el período del orden conservador. Y como herencia de éste, debió enfrentar (ya vimos que buscando atajos simplistas) con la carga que significaba tener franjas de población en condiciones de reproducirse, pero dotadas de muy escasas posibilidades en el campo laboral por sus enfermedades y seguros déficit cognitivos.

Volviendo a la pregunta del comienzo sobre si estos gobiernos populistas generaron una ruptura clara y profunda con el pasado oligárquico, la respuesta parece ser parcialmente negativa. Hubo un cambio importante al institucionalizarse una legislación obrera y la intervención estatal como reguladora del conflicto. Pero fue una institucionalización muy parcial. No hubo una transformación radical (y duradera) al volverse a las reglas del mercado como ordenadoras de la economía regional.

Por ahora carecemos de respuestas para explicar por qué los sectores populares siguieron fielmente al lencinismo durante la década que estuvo en el poder y se mantuvieron con ese sentimiento hasta que la ola peronista los incorporó, condenando a este populismo provinciano al ocaso definitivo.

Recibido: 15/09/2011

Aceptado: 19/11/2011 


\begin{tabular}{|c|c|c|c|c|c|c|c|c|c|c|c|}
\hline & $a^{\circ}$ & & 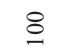 & $\vec{m}$ & $\Xi$ & $\tilde{i}$ & กี & & & & \multirow{21}{*}{ 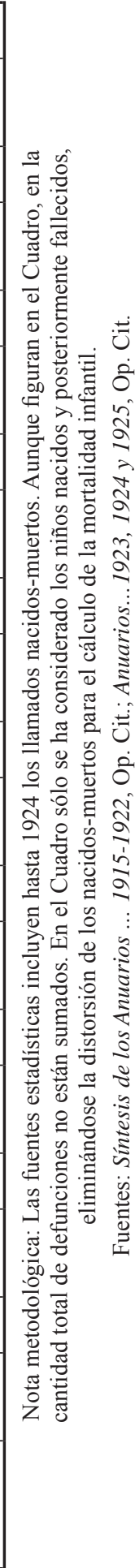 } \\
\hline ชิ & 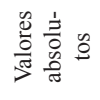 & ñ & $\begin{array}{l}\infty \\
\infty \\
\text { in }\end{array}$ & $\begin{array}{l}\vec{\infty} \\
\stackrel{\infty}{-}\end{array}$ & $\stackrel{\circ}{\infty}$ & $\vec{m}$ & $\stackrel{\infty}{\rightleftharpoons}$ & 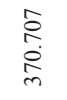 & 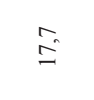 & $\begin{array}{l}\vec{n} \\
0\end{array}$ & \\
\hline \multirow{2}{*}{$\stackrel{\Xi}{\sigma}$} & $\circ^{\circ}$ & & $£$ & m & $\stackrel{\infty}{\longrightarrow}$ & $\tilde{i}$ & $\stackrel{\infty}{+}$ & & & & \\
\hline & 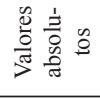 & $\stackrel{\circ}{\circ}$ & $\frac{\infty}{b}$ & $\vec{\circ}$ & $\stackrel{\widetilde{I}}{\leftrightarrows}$ & $\stackrel{n}{=}$ & $\overrightarrow{\widehat{a}}$ & $\begin{array}{l}\text { ర్ } \\
\text { ڤें } \\
\text { ले }\end{array}$ & $\stackrel{\infty}{\infty}$ & $\begin{array}{l}\text { t. } \\
\text { s. } \\
0\end{array}$ & \\
\hline \multirow[b]{2}{*}{$\tilde{\Omega}$} & $0^{\circ}$ & & 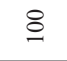 & $\vec{m}$ & $\stackrel{\circ}{-}$ & $\stackrel{+}{i}$ & $\ddot{\text { in }}$ & & & & \\
\hline & 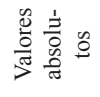 & $\bar{i}$ &  & $\begin{array}{l}\text { Cै } \\
\stackrel{-}{i}\end{array}$ & $\stackrel{\text { 年 }}{\stackrel{-}{-}}$ & I & 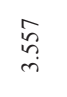 & 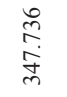 & ते & $\underset{\sigma}{\tilde{O}}$ & \\
\hline \multirow{2}{*}{$\tilde{\Xi}$} & $\circ^{\circ}$ & & 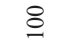 & $m$ & $\stackrel{0}{-}$ & $\vec{i}$ & $\vec{q}$ & & & & \\
\hline &  & $\begin{array}{l}n \\
\infty \\
\infty\end{array}$ & ڤ్ & $\begin{array}{l}\stackrel{\circ}{\circ} \\
\text { i }\end{array}$ & $\stackrel{n}{\alpha}$ & $\stackrel{\overbrace{}}{\simeq}$ & $\begin{array}{l}\text { ડे } \\
\text { ते }\end{array}$ & 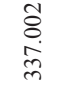 & $\stackrel{\infty}{=}$ & nू. & \\
\hline \multirow{2}{*}{$\bar{\Omega}$} & $\circ^{\circ}$ & & 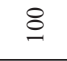 & $\vec{m}$ & 2 & i & $\stackrel{\infty}{+}$ & & & & \\
\hline &  & iे & 尔 & $\begin{array}{l}\vec{\infty} \\
\stackrel{\circ}{-}\end{array}$ & $\stackrel{ }{\stackrel{ }{~}}$ & ț & $\begin{array}{l}\hat{\infty} \\
\dot{r}\end{array}$ & 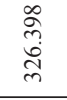 & $\hat{a}$ & $\begin{array}{l}\overrightarrow{0} \\
0\end{array}$ & \\
\hline \multirow{2}{*}{$\stackrel{\Omega}{\Omega}$} & $0^{\circ}$ & & 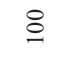 & $\stackrel{n}{m}$ & $\stackrel{\infty}{\infty}$ & $n$ & m & & & & \\
\hline & 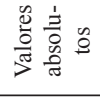 & $\frac{n}{n}$ & $\frac{2}{6}$ & $\begin{array}{l}\mathfrak{n} \\
\hat{\sigma} \\
\stackrel{i}{i}\end{array}$ & $\stackrel{\text { స్ }}{=}$ & $\vec{\infty}$ & $\begin{array}{l}\hat{\circ} \\
\infty \\
\stackrel{i}{i}\end{array}$ & \begin{tabular}{l}
$\infty$ \\
$\infty$ \\
\multirow{\infty}{\infty}{} \\
$\infty$ \\
$m$ \\
$m$
\end{tabular} & $\stackrel{+}{\Omega}$ & $\begin{array}{l}\sqrt{2} \\
0 \\
0\end{array}$ & \\
\hline \multirow[b]{2}{*}{$\stackrel{\vec{\Xi}}{2}$} & $0^{\circ}$ & & 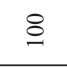 & $\hat{\text { i }}$ & $\vec{\infty}$ & $\hat{i}$ & ì & & & & \\
\hline & 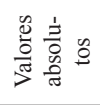 & in & กี & ণু & $\stackrel{n}{m}$ & $\overline{\stackrel{N}{N}}$ & 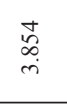 & 을 & $\hat{\vec{\lambda}}$ & $\begin{array}{l}\tilde{6} \\
0\end{array}$ & \\
\hline \multirow{2}{*}{$\stackrel{\infty}{\sigma}$} & $\circ^{\circ}$ & & 8 & $\stackrel{m}{\hat{m}^{n}}$ & $\hat{a}$ & $\stackrel{m}{i}$ & $\stackrel{\vec{f}}{\tilde{\gamma}}$ & & & & \\
\hline & 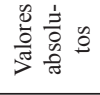 & $\underset{n}{\infty}$ &  & $\stackrel{\hat{n}}{\hat{n}}$ & $\begin{array}{l}\stackrel{2}{2} \\
\stackrel{2}{-}\end{array}$ & $\hat{\Omega}$ & $\stackrel{\infty}{\stackrel{\sim}{\sim}}$ & $\begin{array}{l}\text { ते } \\
\text { ?ें } \\
\vec{d}\end{array}$ & $\overrightarrow{\mathrm{d}}$ & $\begin{array}{l}\hat{\sigma} \\
0\end{array}$ & \\
\hline \multirow{2}{*}{$\stackrel{\bar{\sigma}}{\sigma}$} & $0^{\circ}$ & & 8 & $\stackrel{\vec{m}}{m}$ & $\stackrel{\sim}{\sim}$ & $\stackrel{+}{i}$ & के & & & & \\
\hline & 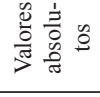 & $\stackrel{8}{\circ}$ & $\stackrel{\infty}{\stackrel{\infty}{ }}$ & $\stackrel{\text { तิ }}{i}$ & $\stackrel{\Xi}{\text { ळ. }}$ & $\stackrel{ \pm}{ \pm}$ & 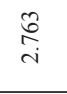 & $\begin{array}{l}\overrightarrow{\tilde{N}} \\
\infty \\
\stackrel{े}{0}\end{array}$ & $\stackrel{\infty}{\tilde{\lambda}}$ & $\frac{n}{0}$ & \\
\hline \multirow{3}{*}{$\stackrel{0}{2}$} & $0^{\circ}$ & &  & ले & $\overbrace{\sigma}^{t}$ & N & $\hat{\tilde{\sigma}}$ & & & & \\
\hline & 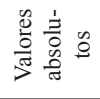 & iิ & బิ & 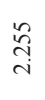 & ơ & $\stackrel{m}{\varrho}$ & $\frac{P}{m}$ &  & $\hat{\tilde{\lambda}}$ & $\stackrel{尺}{\circ}$ & \\
\hline & 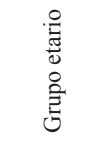 & 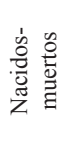 &  & 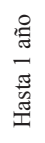 & 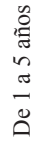 & $\begin{array}{ll}0 & \\
\pi & 0 \\
0 & 0 \\
0 & 0 \\
0 & 0\end{array}$ & 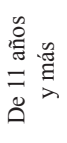 & $\begin{array}{l}\frac{0}{0} \\
\frac{0}{0} \\
\frac{0}{0} \\
0\end{array}$ & 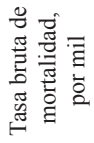 & 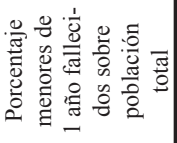 & \\
\hline
\end{tabular}




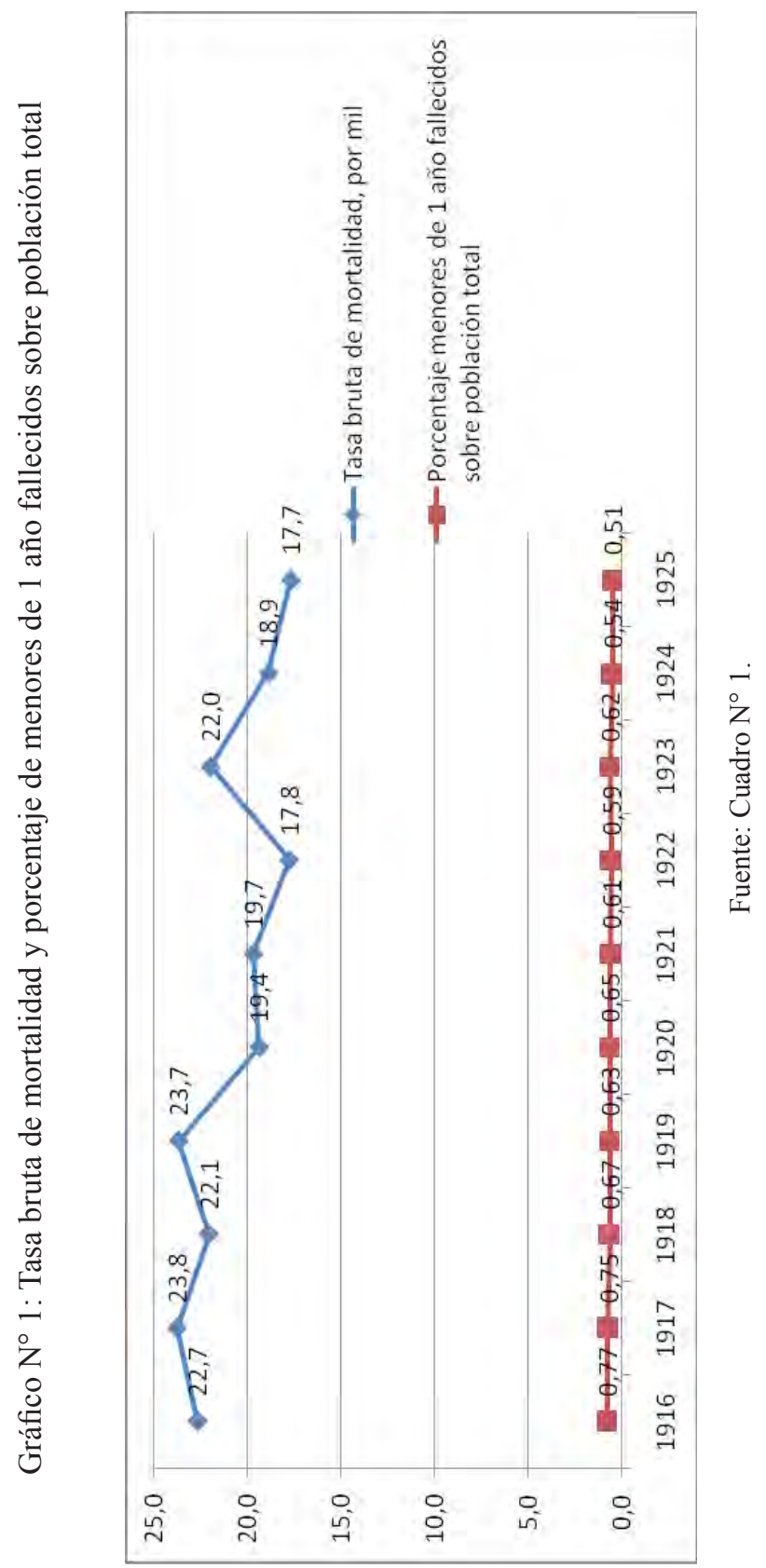


Cuadro No 2: Provincia de Mendoza - Mortalidad infantil 1914 y 1916-1925

\begin{tabular}{|c|c|c|c|}
\hline AÑOS & $\begin{array}{c}\text { TASAS DE } \\
\text { MORTALIDAD }\end{array}$ & $\begin{array}{c}\text { PROMEDIO } \\
\text { NACIDOS VIVOS* }\end{array}$ & $\begin{array}{c}\text { DEFUNCIONES } \\
\text { MENORES DE 1 AÑO }\end{array}$ \\
\hline 1914 & 146,6 & 13.556 & 1.987 \\
\hline 1916 & 177,5 & 12.701 & 2.255 \\
\hline 1917 & 180,8 & 12.371 & 2.237 \\
\hline 1918 & 166,5 & 12.236 & 2.037 \\
\hline 1919 & 158,4 & 12.382 & 1.962 \\
\hline 1920 & 166,6 & 12.457 & 2.075 \\
\hline 1921 & 155,7 & 12.727 & 1.981 \\
\hline 1922 & 149,9 & 13.384 & 2.006 \\
\hline 1923 & 156,8 & 13.791 & 2.162 \\
\hline 1924 & 143,4 & 13.676 & 1.961 \\
\hline 1925 & 138,9 & 13.540 & 1.881 \\
\hline
\end{tabular}

* Se excluyeron los llamados nacidos-muertos, sumandos como nacimientos en la estadística oficial entre 1915 y 1924. Para los nacimientos se ha calculado el promedio entre los ocurridos en el año anterior y los del año considerado en el Cuadro.

Fuentes: elaboración propia con datos tomados de la Síntesis de los Anuarios ... años 1915-1922; Anuario ... 1923, 1924 y 1925, Op. Cit.

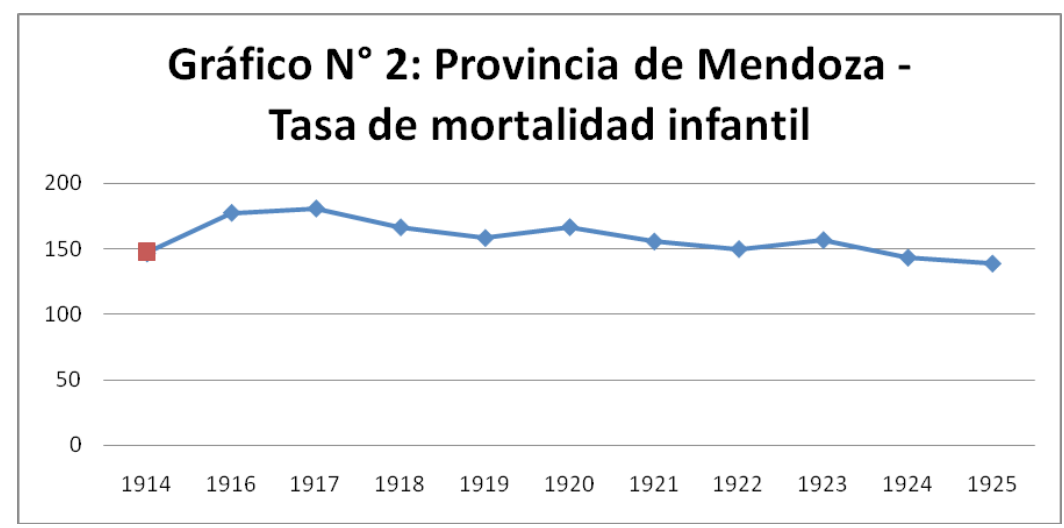

Fuente: Cuadro $\mathrm{N}^{\mathrm{o}} 2$ 


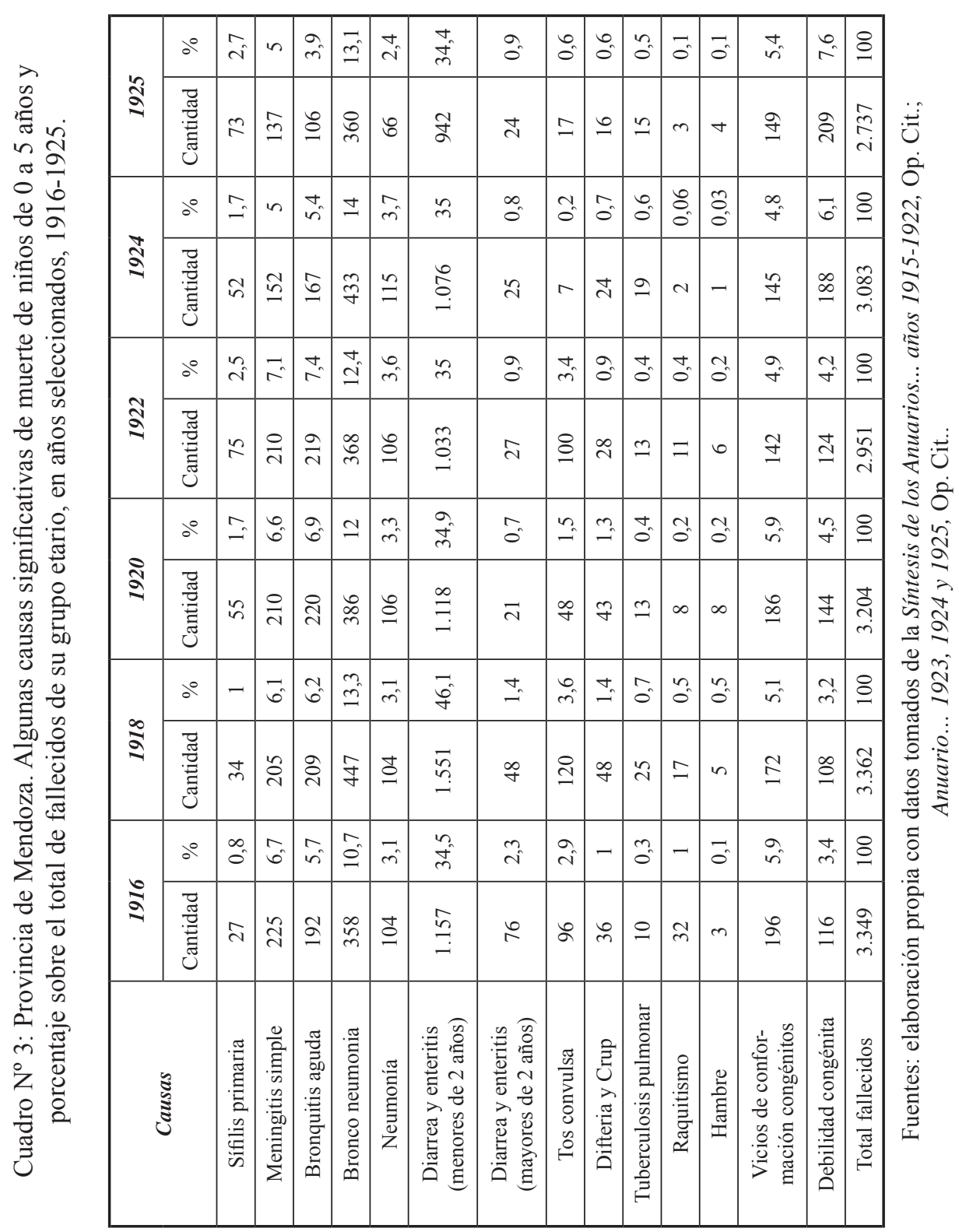


Cuadro $\mathrm{N}^{\mathrm{0}} 4$ : Provincia de Mendoza. Defunciones por lugares principales donde ocurrieron y porcentaje sobre el total, $1916-1925$

\begin{tabular}{|c|c|c|c|c|c|c|c|c|c|c|}
\hline Lugar & $\mathbf{1 9 1 6}$ & $\mathbf{1 9 1 7}$ & $\mathbf{1 9 1 8}$ & $\mathbf{1 9 1 9}$ & $\mathbf{1 9 2 0}$ & $\mathbf{1 9 2 1}$ & $\mathbf{1 9 2 2}$ & $\mathbf{1 9 2 3}$ & $\mathbf{1 9 2 4}$ & $\mathbf{1 9 2 5}$ \\
\hline Casa particular & 5.558 & 5.980 & 5.598 & 6.313 & 5.573 & 5.750 & 5.532 & 6.183 & 5.517 & 5.176 \\
\hline Conventillo & 161 & 234 & 85 & 24 & 18 & 35 & 16 & 15 & 9 & 17 \\
\hline $\begin{array}{c}\text { Establecimientos } \\
\text { benéficos } \\
\text { (Hospitales) }\end{array}$ & 1.270 & 1.180 & 1.337 & 1.324 & 1.093 & 1.211 & 1.018 & 1.392 & 1.244 & 1.324 \\
\hline Vía pública & 32 & 24 & 24 & 31 & 22 & 10 & 23 & 32 & 11 & 21 \\
\hline Total Pcia. & 7.179 & 7.604 & 7.261 & 7.853 & 6.707 & 7.011 & 6.591 & 7.647 & 6.785 & 6.538 \\
\hline \% Casa part. & 77,4 & 78,6 & 77,1 & 80,4 & 83,1 & 82 & 84 & 81 & 81,3 & 79,2 \\
\hline \% Conventillo & 2,2 & 3,1 & 1,2 & 0,3 & 0,3 & 0,5 & 0,2 & 0,2 & 0,1 & 0,2 \\
\hline \% Est. Benéf. & 17,7 & 15,5 & 18,4 & 16,9 & 16,3 & 17,3 & 15,4 & 18,2 & 18,3 & 20,2 \\
\hline \% Vía públ. & 0,4 & 0,3 & 0,3 & 0,4 & 0,3 & 0,1 & 0,3 & 0,4 & 0,1 & 0,3 \\
\hline
\end{tabular}

Nota: en este Cuadro se toma el registro total de defunciones que indican las fuentes, es decir que incluyen los llamados nacidos-muertos, porque no hay manera de excluirlos por ausencia de datos desagregados sobre cada lugar.

Fuentes: elaboración propia con datos tomados de la Síntesis de los Anuarios... años 1915-1922; y Anuario..., 1923, 1924 y 1925, Op. Cit.

Gráfico $\mathrm{N}^{\circ} 3$ :

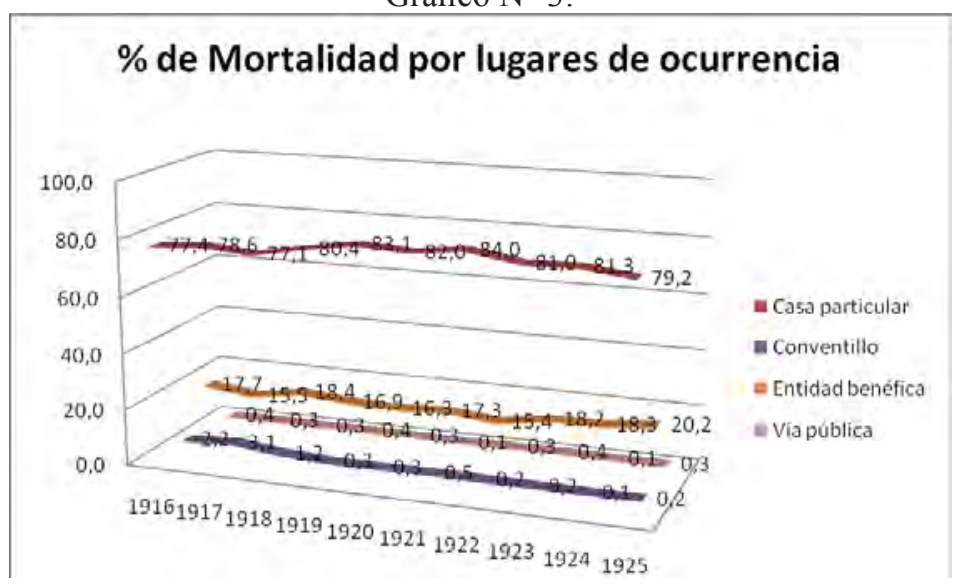

Fuente: Cuadro $\mathrm{N}^{\circ} 4$ 